\title{
Speciated mercury at marine, coastal, and inland sites in New England - Part 2: Relationships with atmospheric physical parameters
}

\author{
H. Mao ${ }^{1}$, R. Talbot ${ }^{2}$, J. Hegarty ${ }^{3}$, and J. Koermer ${ }^{4}$ \\ ${ }^{1}$ Department of Chemistry, State University of New York, College of Environmental Science and Technology, \\ Syracuse, NY 13219, USA \\ ${ }^{2}$ Department of Earth and Atmospheric Sciences, University of Houston, Houston, TX 77204, USA \\ ${ }^{3}$ AER, Inc., 131 Hartwell Avenue, Lexington, MA, 02421, USA \\ ${ }^{4}$ Department of Atmospheric Science \& Chemistry, Plymouth State University, Plymouth, New Hampshire 03264, USA \\ Correspondence to: H. Mao (hmao@esf.edu)
}

Received: 27 September 2011 - Published in Atmos. Chem. Phys. Discuss.: 21 October 2011

Revised: 19 April 2012 - Accepted: 20 April 2012 - Published: 11 May 2012

\begin{abstract}
Long-term continuous measurements of gaseous elemental mercury $\left(\mathrm{Hg}^{0}\right)$, reactive gaseous mercury (RGM), and particulate phase mercury $\left(\mathrm{Hg}^{\mathrm{P}}\right)$ were conducted at coastal (Thompson Farm, denoted as TF), marine (Appledore Island, denoted as AI), and elevated inland rural (Pac Monadnock, denoted as PM) monitoring sites of the AIRMAP Observing Network. Diurnal, seasonal, annual, and interannual variability in $\mathrm{Hg}^{0}$, RGM, and $\mathrm{Hg}^{\mathrm{P}}$ from the three distinctly different environments were characterized and compared in Part 1. Here in Part 2 relationships between speciated mercury (i.e., $\mathrm{Hg}^{0}$, RGM, and $\mathrm{Hg}^{\mathrm{P}}$ ) and climate variables (e.g., temperature, wind speed, humidity, solar radiation, and precipitation) were examined. The best point-to-point correlations were found between $\mathrm{Hg}^{0}$ and temperature in summer at TF and spring at PM, but there was no similar correlation at AI. Subsets of data demonstrated regional impacts of episodic dynamic processes such as strong cyclonic systems on ambient levels of $\mathrm{Hg}^{0}$ at all three sites, possibly through enhanced oceanic evasion of $\mathrm{Hg}^{0}$. A tendency of higher levels of RGM and $\mathrm{Hg}^{\mathrm{P}}$ was identified in spring and summer under sunny conditions in all environments. Specifically, the 10th, 25th, median, 75th, and 90th percentile mixing ratios of RGM and $\mathrm{Hg}^{\mathrm{P}}$ increased with stronger solar radiation at both the coastal and marine sites. These metrics decreased with increasing wind speed at AI indicating enhanced loss of RGM and $\mathrm{Hg}^{\mathrm{P}}$ through deposition. RGM and $\mathrm{Hg}^{\mathrm{P}}$ levels correlated with temperature positively in spring, summer
\end{abstract}

and fall at the coastal and marine locations. At the coastal site relationships between RGM and relative humidity suggested a clear decreasing tendency in all metrics from $<40 \%$ to $100 \%$ relative humidity in all seasons especially in spring, compared to less variability in the marine environment. The effect of precipitation on RGM at coastal and marine locations was similar. At the coastal site, RGM levels were a factor of 3-4 to two orders of magnitude higher under dry conditions than rainy conditions in all seasons. In winter RGM mixing ratios appeared to be mostly above the limit of detection (LOD) during snowfalls suggesting less scavenging efficiency of snow. Mixing ratios of $\mathrm{Hg}^{\mathrm{P}}$ at the coastal and marine sites remained above the LOD under rainy conditions. Precipitation had negligible impact on the magnitude and pattern of diurnal variation of $\mathrm{Hg}^{\mathrm{P}}$ in all seasons in the marine environment.

\section{Introduction}

Mercury is a dangerous toxin detrimental to human health and thus it is of paramount importance to understand the processes that control the ambient levels of atmospheric mercury. Mercury exists in three forms, gaseous elemental mercury $\left(\mathrm{Hg}^{0}\right)$, reactive gaseous mercury (RGM), and particulate phase mercury $\left(\mathrm{Hg}^{\mathrm{P}}\right)$. Mercury cycling, i.e., transformation between the three forms, is intricately linked to dynamical, 
physical and chemical processes in the atmosphere. Moreover, source and sink strengths of $\mathrm{Hg}^{0}$ are dependent on physical parameters such as temperature and wind. However, Jacob and Winner (2009) pointed out that the effect of longterm changing physical parameters (i.e., climate changes) on mercury cycling has received no attention to date.

Previous research has been conducted to examine the relationships between mercury and physical variables over a limited time period ranging from days to one or two years, which appeared to vary greatly at various geographic locations. For example, Gårdfeldt et al. (2003) found from their one month campaign over the Atlantic and two month measurements over the Mediterranean Sea that mercury evasion from sea water depended on temperature, wind, and salinity. Han et al. (2004) attributed a negative correlation between total gaseous mercury (TGM) and temperature to seasonal difference in emission rates of coal-fired power plants (winter maximum) in the northern hemisphere based on two summers of measurement data. A negative correlation between temperature and TGM was shown by measurements during a winter month at a rural site in the central Pearl River Delta region ( $\mathrm{Li}$ et al., 2011). A ten month data set at Elora, Ontario, Canada suggested highest $\mathrm{Hg}^{0}$ concentrations in late spring and fall possibly due to increases in air temperature among other factors in spring and lower atmospheric mixing height in fall (Baya and Van Heyst, 2010). This relationship was supported by our study (Sigler et al., 2009a) with significant positive correlation between seasonally averaged $\mathrm{Hg}^{0}$ and temperature in spring and fall 2007 at a coastal and marine site from southern New Hampshire. Ambient levels of $\mathrm{Hg}^{0}$ and TGM were also found to be correlated with solar radiation, relative humidity, and planetary boundary layer height (Cobbetta et al., 2007; Stamenkovic et al., 2007).

Reactive mercury was reportedly linked to temperature, radiation, humidity and precipitation. Sigler et al. (2009a) presented a positive relationship between seasonal averaged RGM and temperature at a coastal site whereas none from the marine site. Transformation from $\mathrm{Hg}^{0}$ to RGM by oxidation involves photochemistry (Lin et al., 1999), which indicates a link between RGM concentrations and solar radiation. Indeed, studies have shown the diurnal patterns of RGM and radiation flux were close in phase (Mason and Sheu, 2002; Spovieri et al., 2003; Sigler et al., 2009a). Laurier et al. (2003) observed the concurrence of highest RGM and maximum UV radiation flux in the marine boundary layer over the North Pacific Ocean. Highest RGM levels were observed around midday after nights of high relative humidity, while lowest concentrations were found during high relative humidity and rainfall (Mason and Sheu, 2002; Laurier et al., 2003, 2007; Poissant et al., 2004, 2005).

There are limited long-term data sets of $\mathrm{Hg}^{\mathrm{P}}$, and their relationships with physical variables suggested that high levels were mostly associated with wind driven transport, chemical and physical transformation processes. For instance, two years of daily measurements of $\mathrm{Hg}^{\mathrm{P}}$ in the fine $(<2.5 \mu \mathrm{m})$ and coarse $(>2.5 \mu \mathrm{m})$ fractions in New York from Ames et al. (1998) suggested impact on fine particles from regional sources in the midwestern US and impact on coarse particles from local aluminum processing facilities. The one-year $\mathrm{Hg}^{\mathrm{P}}$ dataset from Poissant et al. (2005) exhibited higher levels of $\mathrm{Hg}^{\mathrm{P}}$ associated with transport, RGM gas-particle partitioning, and $\mathrm{Hg}^{0}$ oxidation. Liu et al. (2007) suggested that the diurnal pattern of $\mathrm{Hg}^{\mathrm{P}}$ (as well as that of $\mathrm{Hg}^{0}$ ) was strongly influenced by boundary layer dynamics, temperature and humidity based on their one year measurements in Detroit, MI. Similarly, Brooks et al. (2010) found that during a summer campaign in Houston, TX, peaks of $\mathrm{Hg}^{\mathrm{P}}$ (as well as $\mathrm{Hg}^{0}$ and RGM) showed distinct and consistent relationships with the average planetary boundary layer dynamics, which were enhanced in a shallow nocturnal boundary layer.

Wind data have been used to trace back the origin of high mercury concentrations. Some studies often found association between high concentrations of mercury and wind direction which points to upwind source regions (e.g., Gabriel et al., 2005; Poissant et al., 2005; Aucott et al., 2009; Sigler et al., 2009a; Baya and van Heyst, 2010), while others detected no correlation (Castillo et al., 2011). In addition, our previous study found a relationship between wind speed and possible oceanic evasion (Sigler et al., 2009b). We hypothesized the impact of the April 2007 Nor'easter on ambient levels of $\mathrm{Hg}^{0}$ that were reflected in sudden enhancements of 52 ppqv and 26 ppqv over a span of 14 and $12 \mathrm{~h}$ at a coastal and inland site, respectively.

While long-term studies of TGM have been conducted, few studies have been dedicated to the investigation of longterm relationships between speciated mercury and physical parameters. Six-year measurement datasets from Mace Head, Ireland and Zingst, Germany showed a strong positive correlation TGM bore with wind and dew point (Kock et al., 2005). Cole and Steffen (2010) found a positive correlation between $\mathrm{Hg}^{0}$ and air temperature from their $12 \mathrm{yr}$ (1995-2007) measurement data in Alert, Canada although it was not clear if temperature was the direct cause of the $\mathrm{Hg}^{\mathrm{O}}$ variability. Long-term measurements of speciated mercury have been conducted at inland, coastal, and marine locations in southern New Hampshire. This study is Part 2 of a three paper series. Part 1 focuses on key characteristics of $\mathrm{Hg}^{0}$, $\mathrm{RGM}$, and $\mathrm{Hg}^{0}$ variations ranging from diurnal to interannual time scales and their differences between locations with distinct geographical characteristics (Mao and Talbot, 2011). In this study we investigated how the three forms of mercury are associated with atmospheric conditions via their relationships with climate variables in different environments. In Part 3, we will further understand the key findings from Parts 1 and 2 using potential relationships between speciated mercury and other trace gases. 


\section{Measurements and approach}

As stated in Mao and Talbot (2011), multiple-year measurements of $\mathrm{Hg}^{0}, \mathrm{RGM}$, and $\mathrm{Hg}^{\mathrm{P}}$ have been conducted at three AIRMAP (www.airmap.unh.edu) Observatory sites: Thompson Farm $\left(43.11^{\circ} \mathrm{N}, 70.95^{\circ} \mathrm{W}, 24 \mathrm{~m}\right.$ a.g.l.) (TF), Pac Monadnock $\left(42.86^{\circ} \mathrm{N}, 71.88^{\circ} \mathrm{W}, 700 \mathrm{~m}\right.$ a.s.l.) (PM), and Appledore Island $\left(42.97^{\circ} \mathrm{N}, 70.62^{\circ} \mathrm{W}, 40 \mathrm{~m}\right.$ a.g.l.) (AI). The PM and TF sites are 185 and $25 \mathrm{~km}$, respectively, inland from the Atlantic Ocean, while AI is $10 \mathrm{~km}$ offshore in the Gulf of Maine. The locations of the three sites form a unique westeast oriented transect with site surroundings composed of heavily forested, coastal, and marine boundary layer environments. Moreover, due to the remote central location of PM in New England and its $700 \mathrm{~m}$ elevation (i.e., above the nocturnal inversion and in the middle of the daytime boundary layer), the site is ideally located to determine regional trends in trace gases, including mercury (Mao et al., 2008).

Mercury instruments were operated in a manner identical at TF (coastal), PM (inland), and AI (marine) to ensure data consistency. Details of the instruments can be found in Mao et al. (2008), Sigler et al. (2009a), and Mao and Talbot (2011). Briefly, a Tekran 1130 denuder module operated in series with the $2537 \mathrm{~A}$ provided continuous measurements of RGM and $\mathrm{Hg}^{0}$ respectively. Ambient mixing ratios of $\mathrm{Hg}^{0}$ were measured continuously using the $2537 \mathrm{~A}$ cold vapor atomic fluorescence spectrometer with 5-min time resolution and a limit of detection (LOD) of $\sim 10 \mathrm{ppqv}\left(1 \mathrm{ng} \mathrm{m}^{-3}=\right.$ 112 ppqv). RGM is measured with a 90 min sampling interval yielding a LOD of $\sim 0.1$ ppqv based on three times the standard deviation of the field blank values determined at TF (coastal) during 2007. The inlet of the Tekran 1135 for measuring $\mathrm{Hg}^{\mathrm{P}}$ at $\mathrm{AI}$ (marine) was modified by replacing the elutriator with one that contained no impaction plate to facilitate collection of coarse aerosols on the quartz frit in the Tekran 1135 (Talbot et al., 2011).

Continuous $\mathrm{Hg}^{0}$ measurements with 5-min resolution started in November 2003 at TF (coastal), December 2004 at PM (inland), and June 2007 at AI (marine). Measurements of RGM with 2-h resolution were added at TF (coastal) in November 2006, December 2006 at PM (inland), and on AI (marine) in June 2007. Measurements of $\mathrm{Hg}^{\mathrm{P}}$ started at $\mathrm{TF}$ (coastal) in February 2009 and on AI (marine) in April 2009. The end of the study period is 31 August 2010 for all datasets except RGM measurements at PM (inland) which were decommissioned in October 2008.

Data of temperature, wind, relative humidity, solar radiation (in the form of $j \mathrm{NO}_{2}$ at $\mathrm{AI}$, marine) were obtained from the long term meteorological measurements by AIRMAP at TF (coastal), PM (inland), and AI (marine). This is complemented by hourly precipitation and radiation flux data from the NOAA's US Climate Reference Network site co-located at TF (coastal) (publicly available at http://www.ncdc.noaa. gov/crn/products.html), as well as 6-hourly precipitation data from NOAA's National Weather Service site at Pease, NH which is the closest approximation for data on AI (marine). Where there was a significant fraction of wind and temperature data missing on AI (marine) due to power shortage under extreme weather conditions, GoMOOS meteorological data from the site on Star Island was used as substitute. The two islands were merely a few tens meters apart and their overlapping data of temperature and wind were verified to be correlated at $r^{2}>0.9$. GoMOOS data are publicly available (http://www.gomoos.org/data/recent.html).

Measurement data of carbon monoxide (CO) were used in this study in determining anthropogenic influence. A detailed study of relationships between $\mathrm{Hg}^{0} / \mathrm{RGM} / \mathrm{Hg}^{\mathrm{P}}$ and other chemical compounds will be presented in Part 3 (Mao et al., 2012). A description of $\mathrm{CO}$ measurement can be found in Mao and Talbot (2004a).

All data are presented in Coordinated Universal Time (UTC) with local time corresponding to UTC-5 h for nondaylight saving time intervals and UTC- $4 \mathrm{~h}$ when daylight saving was in effect (i.e., April-October before 2007; March-November after 2007).

\section{Relationships between $\mathrm{Hg}^{0} / \mathrm{RGM} / \mathrm{Hg}^{\mathrm{P}}$ and meteorological parameters}

\subsection{Wind}

One of the most significant sources of mercury at the three locations would be anthropogenic emissions, as the AIRMAP Observing Network is located downwind of major industrial sources and metropolitan areas. Moreover, Sigler et al. (2009b) reported enhancements of $30-50$ ppqv in $\mathrm{Hg}^{0}$ mixing ratios at TF (coastal) and at PM (inland) during the most intense period of the April 2007 Nor'easter and hypothesized that it was due to strong wind induced oceanic emissions. Therefore, it is logical to speculate on an association between $\mathrm{Hg}^{0}$ levels and wind speed and direction. Yet, seasonal scatter plots of $\mathrm{Hg}^{0}$ mixing ratios versus wind speed and directions at TF (coastal), AI (marine), and PM (inland) did not reveal distinct relationships.

However, a close examination of a subset of data revealed association between $\mathrm{Hg}^{0}$ mixing ratios and wind speed at AI (marine), as suggested in Fig. 1a, where the majority of the measurements were taken during the time periods of 22-29 October and the month of November 2008. Interestingly there appeared to be a 3-4 day periodicity in $\mathrm{Hg}^{0}$ mixing ratios during the time period of 22 October30 November 2008 (Fig. 1a). Some periods of higher $\mathrm{Hg}^{0}$ levels coincided with higher $\mathrm{CO}$ levels and others showed $\mathrm{Hg}^{0}$ and $\mathrm{CO}$ in opposite phases. A particular interesting case is the one over 14-16 November 2008, when $\mathrm{Hg}^{0}$ and wind speed was correlated at $r^{2}=0.18$ and slope $=3.7 \mathrm{ppqv}$ per $\mathrm{m} \mathrm{s}^{-1}$ (Fig. 1b, c). The $\mathrm{Hg}^{0}$ mixing ratio started increasing in the early morning and was enhanced by $\sim 70$ ppqv reaching $205 \mathrm{ppqv}$ in $24 \mathrm{~h}$, and this increase, somewhat dampened 

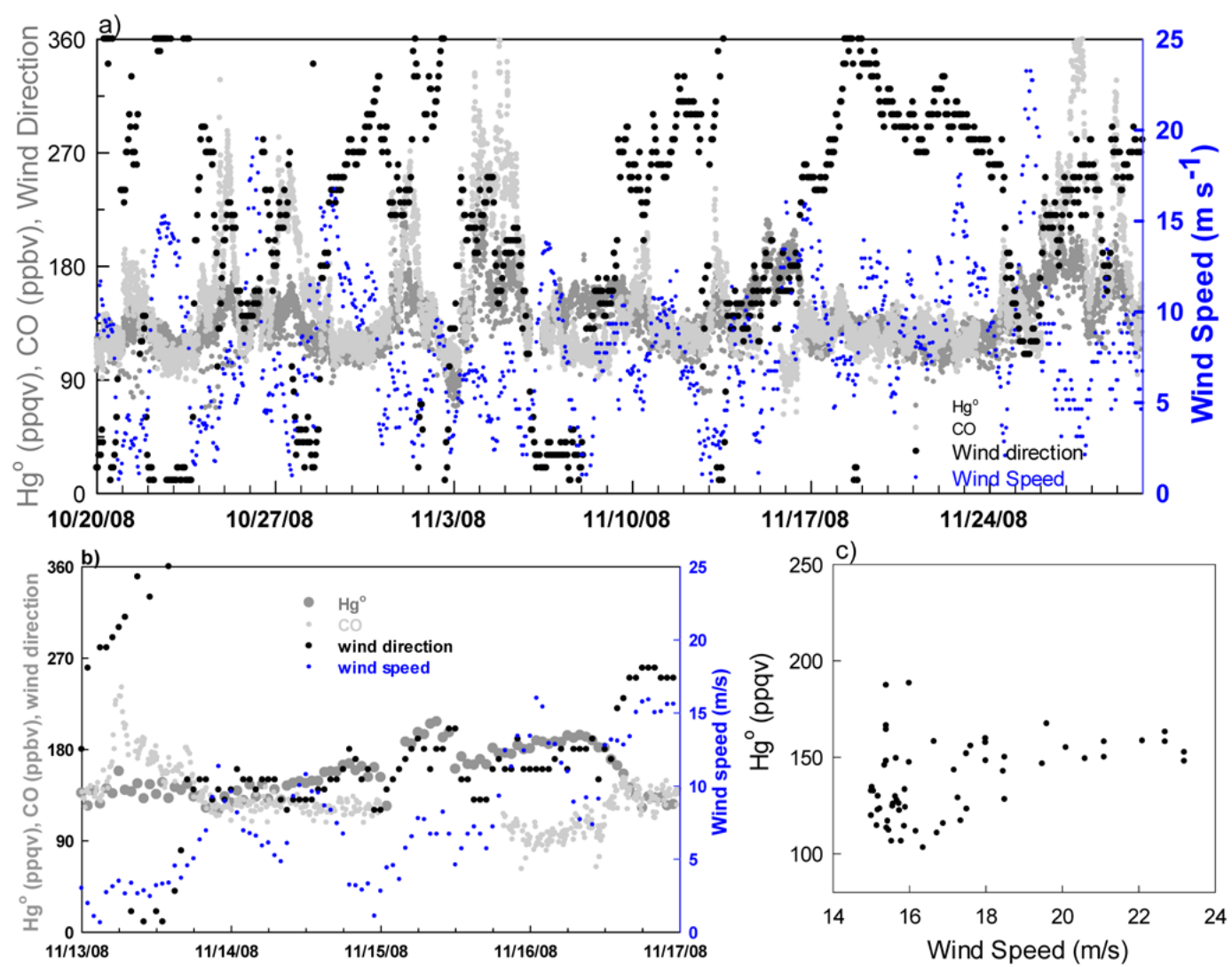

Fig. 1. (a) Wind speed (blue dots) and direction (solid black circles), mixing ratios of $\mathrm{Hg}^{0}$ (dark grey) and CO (light grey) at AI (marine) during 20 October-30 November 2008, (b) a zoom-in on 13-17 November 2008 and (c) the $\mathrm{Hg}^{0}$-wind speed correlation with $r^{2}=0.18$, slope $=3.7$ ppqv per $1 \mathrm{~m} \mathrm{~s}^{-1}$ for the zoom-in period.

later on, lasted through midday 16 November. During the hours of the first $\mathrm{Hg}^{0}$ peak on 15 November $\mathrm{CO}$ measurements were not available; during the hours of the second $\mathrm{Hg}^{0}$ peak on 16 November, $\mathrm{CO}$ mixing ratios were decreased by $\sim 40$ ppbv to as low as $\sim 90$ ppbv at 00:00. The wind direction appeared to be varying in the two easterly quadrants and was mostly southerly and southeasterly at the times of the $\mathrm{CO}$ minimum and $\mathrm{Hg}^{0}$ maximum. This indicates that the increase of $\mathrm{Hg}^{0}$ on 16 November was likely influenced by an influx of air from the relatively clean oceanic region.

To support our speculation, we examined the dynamic patterns during 14-16 November 2008. During this time period New England was impacted by a strong cyclone with sustained coastal surface winds exceeding $15 \mathrm{~m} \mathrm{~s}^{-1}$ and periods of widespread heavy rainfall. At 00:00 UTC on 16 November the cyclone was located in upstate New York near the Canadian border with a central sea level pressure of $990 \mathrm{hPa}$ (Fig. 2) and produced strengthening southerly and southeasterly surface winds at AI (marine) and surrounding coastal and marine locations during the afternoon of 15 November and into the morning of 16 November. The wind speed measured at AI (marine) increased from $\sim 3 \mathrm{~m} \mathrm{~s}^{-1}$ at 00:00 UTC on 15 November to $\sim 8 \mathrm{~m} \mathrm{~s}^{-1}$ in $12 \mathrm{~h}$, then after a slight slow- ing during that afternoon increased steadily to a peak value greater than $16 \mathrm{~m} \mathrm{~s}^{-1}$ by 00:00 UTC on 16 November. The winds at AI (marine) shifted into the southwesterly and then northwesterly direction during the day on 16 November before gradually slowing during the next day as the cyclone center moved northeastward into eastern Canada. The evolution of dynamic processes during 14-16 November suggested unusually strong winds from a maritime direction that coincided in time with the onset of the sudden increase in $\mathrm{Hg}^{0}$.

We also examined $\mathrm{Hg}^{0}$ mixing ratios during the same time period for TF (coastal) and PM (inland) (Fig. 3). Prior to the storm there were distinct diurnal cycles at TF (coastal) with the daily maximum in the late afternoon followed by a steady decrease to the daily minimum before sunrise. On 13 November the $\mathrm{Hg}^{0}$ mixing ratio kept rising during the day, and the increasing trend continued through 14 November leveling off at 173 ppqv on 15 November and then hovered around that level until 12:00 UTC of 16 November (Fig. 3a). PM (inland) experienced an increase during 14-15 November that was similar to the one at TF (coastal) followed by a slowed decrease on 15 November (Fig. 3b). These somewhat synchronized changes in $\mathrm{Hg}^{0}$ mixing ratios at the three sites during 


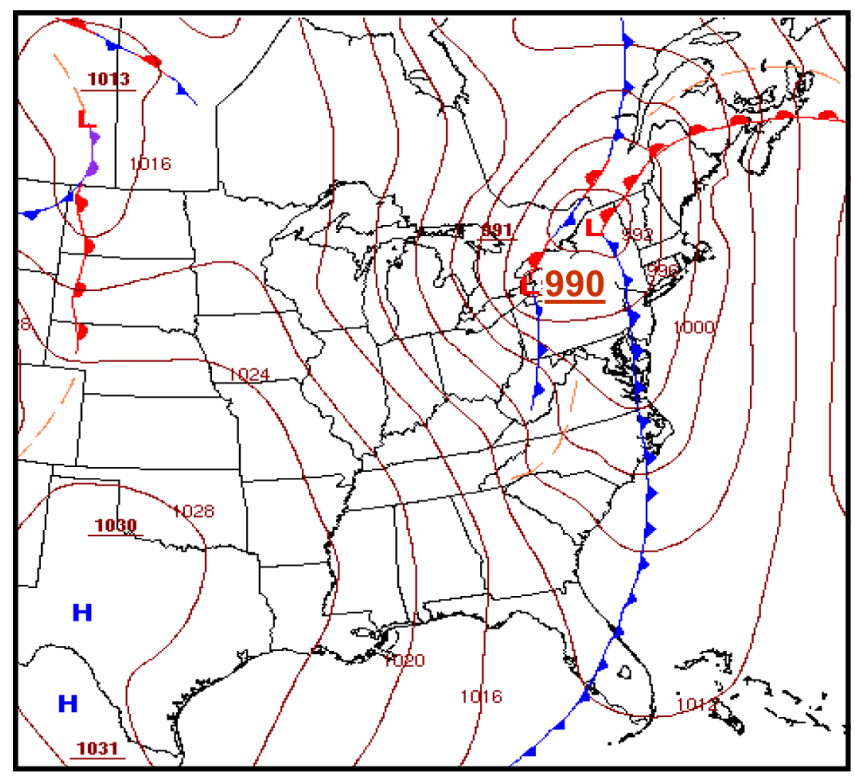

Fig. 2. Surface analysis from the Hydrometeorological Prediction Center (http://www.hpc.ncep.noaa.gov/) for 00:00 UTC, 16 November 2008. Sea level pressure is contoured with reddish brown lines every $4 \mathrm{hPa}$. Cold (blue), warm (red), and occluded (purple) frontal positions are also shown and central pressures $(\mathrm{hPa})$ of highs and lows are shown with underlined numbers.

the storm supported our hypothesis in Sigler et al. (2009b) that strong wind induced enhancement in oceanic emissions of $\mathrm{Hg}^{0}$ can have a regional influence on ambient levels of $\mathrm{Hg}^{0}$ that can reach far inland.

At TF (coastal) $50 \%$ of the total RGM data were collected under wind speed $<1 \mathrm{~m} \mathrm{~s}^{-1}$, which nearly all occurred at night (00:00-11:00 UTC) and before noon local time (12:00-17:00 UTC), and over this range of wind speed, the median and 75th percentile values were lowest (Fig. 4a). The largest 75 th percentile value $(0.6 \mathrm{ppqv})$ was associated with wind speed $2-3 \mathrm{~ms}^{-1}$ (Fig. 4a). Overall, under conditions of wind speed $>2 \mathrm{~m} \mathrm{~s}^{-1}$, nearly $90 \%$ of the data points were collected during the day (12:00-23:00 UTC) and before midnight local time (00:00-05:00 UTC), and over half of the data points were sampled in the afternoon local time (18:00-23:00 UTC). The wind rose of RGM (Fig. 4b) showed that mixing ratios over $0.6-3$ ppqv occurred in all wind directions except over the ranges of $330-360^{\circ}$ and 0 $45^{\circ}$. RGM $>3$ ppqv occurred in two ranges: southeasterly $\left(\sim 135^{\circ}\right)$ and southerly to northwesterly $\left(180-315^{\circ}\right)$, which have been proved in our previous studies to be the flow regimes that facilitated pollutant transport from sources in the Northeast (Mao and Talbot, 2004b).

Compared to TF (coastal), winds were stronger at AI (marine), and RGM mixing ratios appeared to be less dependent on wind speed, which is evidenced in median values of 0.2 ppqv in all wind speed ranges except the median value below the LOD for wind speed greater than $10 \mathrm{~m} \mathrm{~s}^{-1}$ (Fig. 4c).
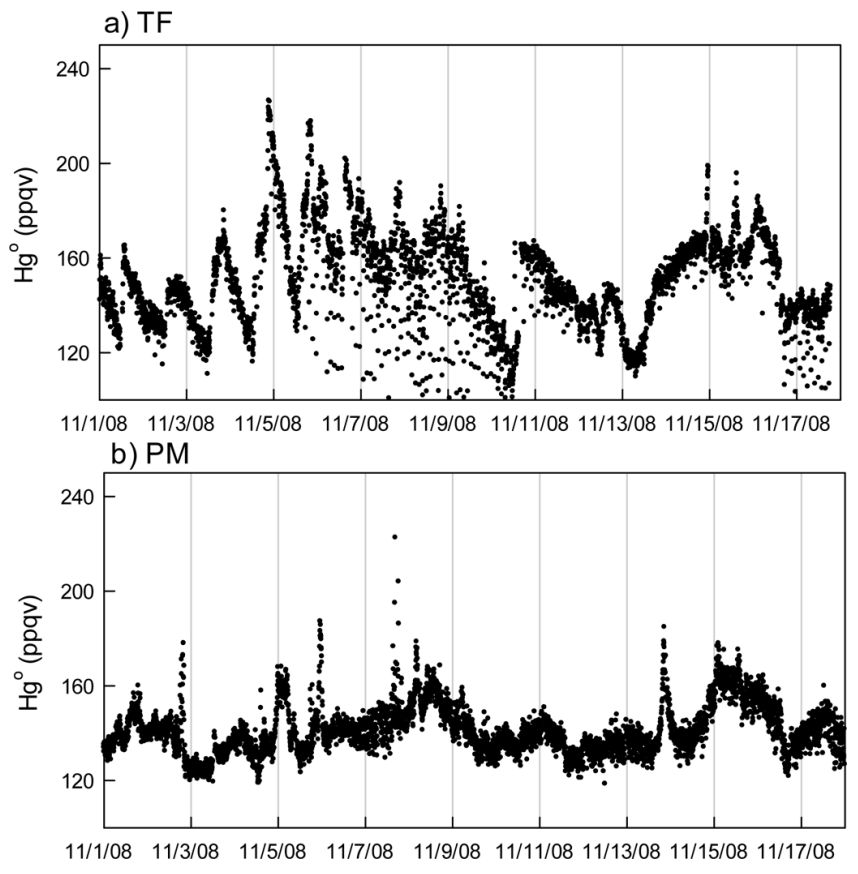

Fig. 3. $\mathrm{Hg}^{0}$ mixing ratios at $\mathrm{TF}$ (coastal) (a) and PM (inland) (b) during the time period of 1-17 November 2008.

The 75th percentile value varied from $0.3 \mathrm{ppqv}$ at winds exceeding $10 \mathrm{~m} \mathrm{~s}^{-1}$ to $0.6 \mathrm{ppqv}$ at winds $<6 \mathrm{~m} \mathrm{~s}^{-1}$. The wind rose (Fig. 4d) suggested that the majority of RGM mixing ratios $>1$ ppqv were observed in all directions, but the few ones $>4$ ppqv, which occurred in spring, were mostly from the south and the west, whose upwind source regions are the greater Boston area and southern $\mathrm{NH}$.

At PM (inland) median values of RGM mixing ratios in all wind ranges remained consistently below the LOD; the 75th percentile values barely reached the LOD (Fig. 4e). The majority of RGM mixing ratios $>0.2$ ppqv were observed in two primary wind direction ranges, east and southwest (Fig. 4f) in the four seasons of 2007, with a few samples from the southeast. There are two coal-fired power plants southwest of PM (inland) near Springfield, MA (Solution, Inc and Northeastern Utilities), one southeast of PM (inland) in Salem, MA (Dominion Salem Harbor), and two east of PM (inland) in NH. Possibly on days with favorable wind conditions influence of these power plant emissions could reach PM (inland).

The relationship between $\mathrm{Hg}^{\mathrm{P}}$ and wind speed at $\mathrm{TF}$ (coastal) suggested no wind dependence of all metrics of $\mathrm{Hg}^{\mathrm{P}}$, including 25th percentile, median, and 75th percentile values, on wind direction over all ranges of wind speed (Fig. 5a, b). A handful of data greater than 1 ppqv turned out to be collected exclusively on several days over 4 February15 March 2009 coming from southeast to northwest. Such levels of $\mathrm{Hg}^{\mathrm{P}}$ were hardly observed beyond that season. Three-day backward trajectories suggested that air masses with higher $\mathrm{Hg}^{\mathrm{P}}$ levels originated from southern Canada or 

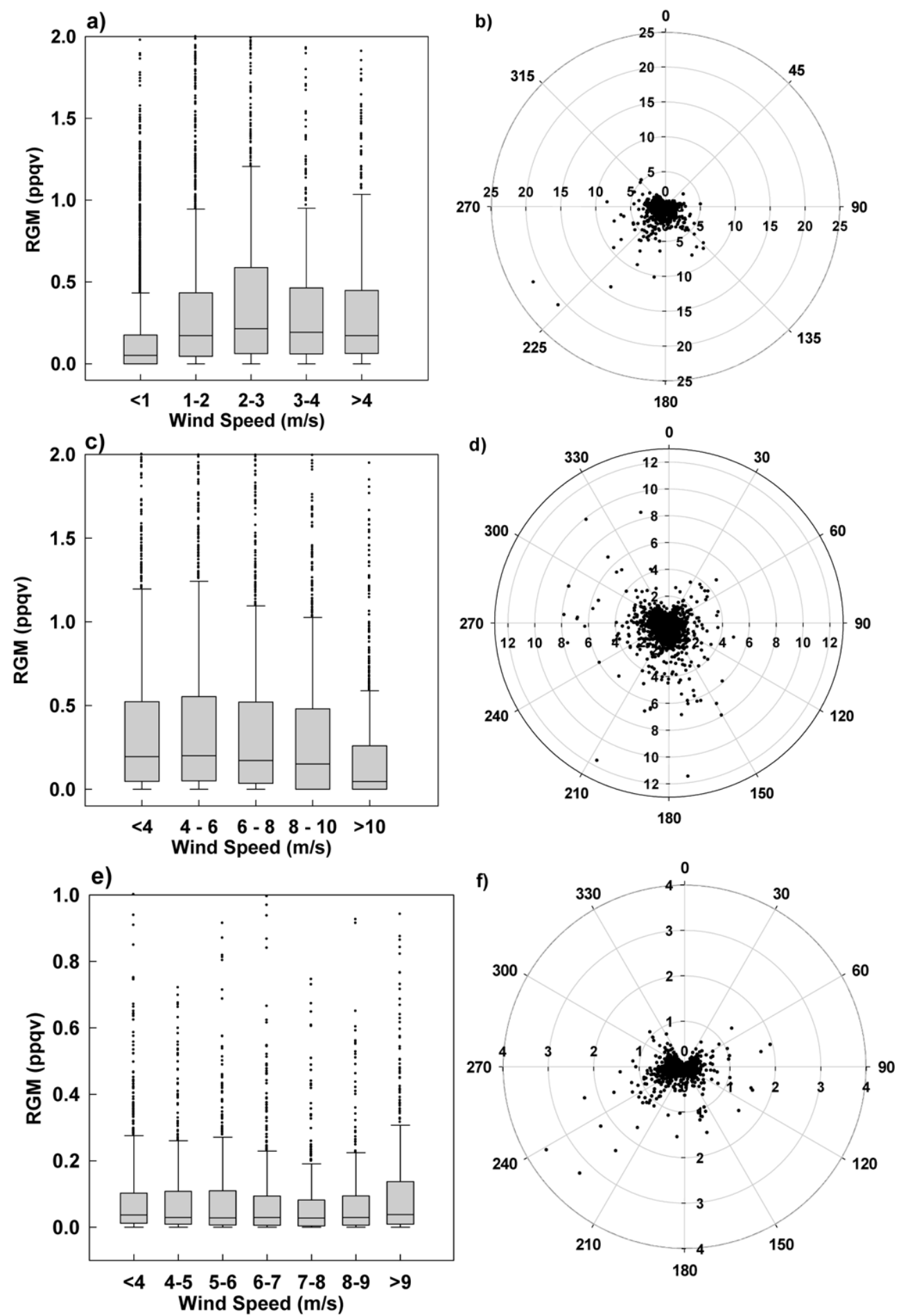

Fig. 4. RGM mixing ratios versus wind speed and direction at TF (coastal) (a, b), AI (marine) (c, d), and PM (inland) (e, f).

eastern to southern US via sweeping southerly to northwesterly flows from the 500 to $2000 \mathrm{~m}$ altitude. The same back trajectories run for air masses with low $\mathrm{Hg}^{\mathrm{P}}$ levels during the same time period did not appear to be vastly different. It is unclear why the highest $\mathrm{Hg}^{\mathrm{P}}$ mixing ratios were measured during winter 2009.

Unlike the TF (coastal) location, at AI (marine) there appeared to be a decreasing tendency in $\mathrm{Hg}^{\mathrm{P}}$ mixing ratios with increasing wind speed (Fig. 5c). In particular, the 

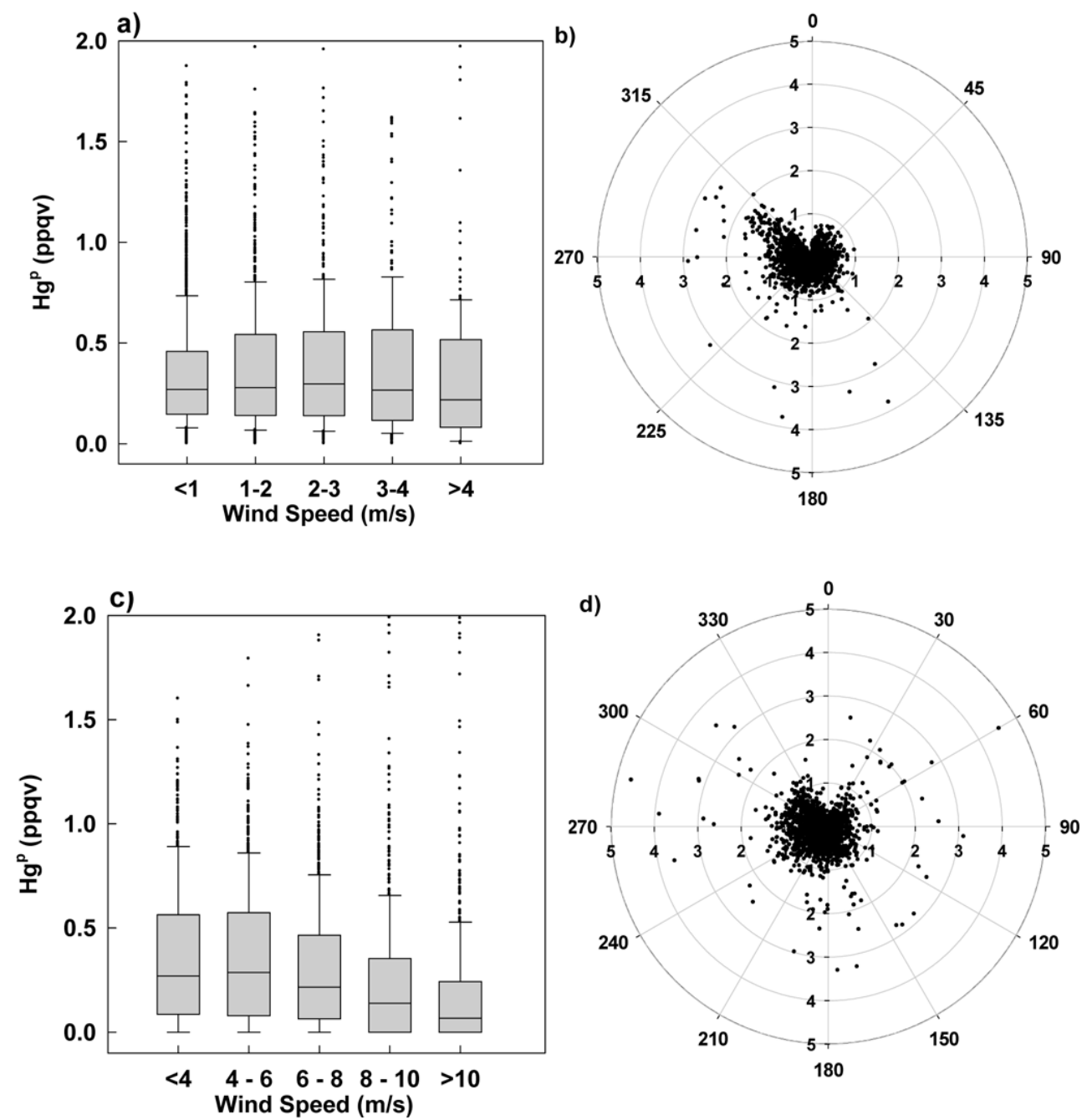

Fig. 5. $\mathrm{Hg}^{\mathrm{P}}$ mixing ratios versus wind speed and wind direction at $\mathrm{TF}$ (coastal) (a, b) and $\mathrm{AI}$ (marine) (c, d).

75th percentile value decreased from $0.6 \mathrm{ppqv}$ at wind speed $<6 \mathrm{~m} \mathrm{~s}^{-1}$ to $0.2 \mathrm{ppqv}$ at wind speed $>10 \mathrm{~m} \mathrm{~s}^{-1}$, and the trend in median values for all wind speed ranges was similar but the decrease rate was slowed by one-half. For samples with $\mathrm{Hg}^{\mathrm{P}}>1.5 \mathrm{ppqv}$, air masses seemed to come from all directions, whereas air with $\mathrm{Hg}^{\mathrm{P}}$ over the range of $0.5-1.5 \mathrm{ppqv}$ was more prevalent in the westerly flow indicating a land influence (Fig. 5d).

\subsection{Solar radiation}

The relationship of $\mathrm{Hg}^{0}$, RGM, or $\mathrm{Hg}^{\mathrm{P}}$ with solar radiation was examined using $\mathrm{Hg}^{0}$, RGM, or $\mathrm{Hg}^{\mathrm{P}}$ versus surface solar radiation flux at TF (coastal) while versus $j \mathrm{NO}_{2}$ at $\mathrm{AI}$ (marine) for daytime: 12:00-18:00 UTC and 18:00-00:00 UTC. No measurements of solar radiation were available at PM (inland). No relationship between $\mathrm{Hg}^{0}$ and solar radiation was observed at TF (coastal) and AI (marine) for the two day- time quadrants in all seasons, and thus we focus on RGM and $\mathrm{Hg}^{\mathrm{P}}$.

For RGM at TF (coastal), a positive tendency with increasing solar radiation in spring was observed in the 25th, median, and 75th percentile values, while at AI (marine) a positive tendency was found in both spring and summer (Fig. 6a, b). The increase with radiation flux was more significant at TF (coastal) with the median value rising from 0.4 to 1.4 ppqv compared to a lesser increase from 0.1 to 0.4 ppqv at $\mathrm{AI}$ (marine). For $\mathrm{Hg}^{\mathrm{P}}$, its positive tendency with increasing solar radiation was observed in summer at both TF (coastal) and AI (marine) (Fig. 6c, d). One exception is that at $\mathrm{AI}$ (marine), the increasing tendencies in the 25th, median, and 75th percentile values of $\mathrm{Hg}^{\mathrm{P}}$ turned downward at $j \mathrm{NO}_{2}$ $>0.008 \mathrm{~s}^{-1}$. 

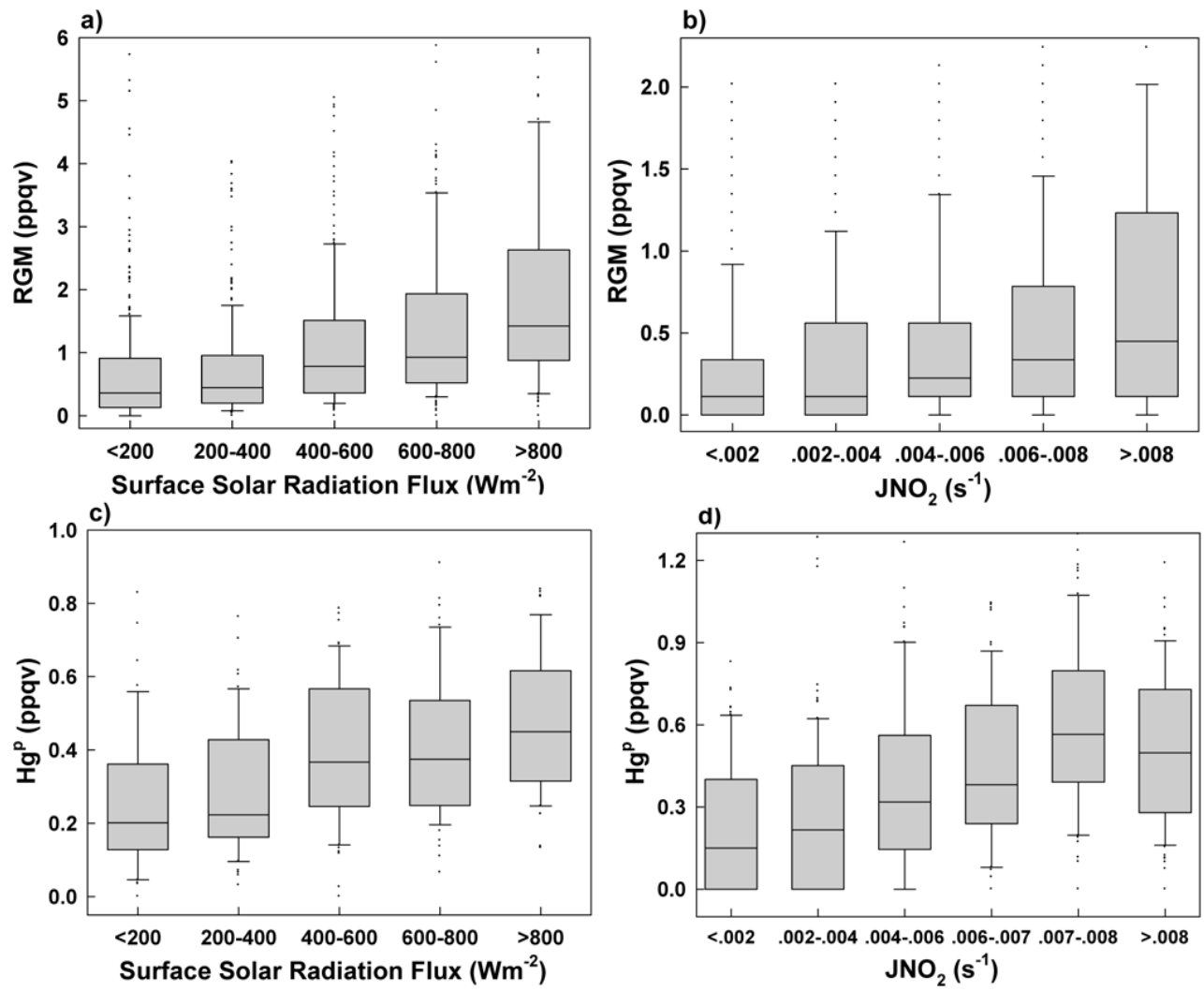

Fig. 6. (a) RGM versus surface solar radiation flux at TF (coastal) in spring, (b) $\mathrm{RGM}$ versus $j \mathrm{NO}_{2}$ at $\mathrm{AI}$ (marine) in spring and summer, (c) $\mathrm{Hg}^{\mathrm{P}}$ versus surface solar radiation flux at $\mathrm{TF}$ (coastal) in summer, and (d) $\mathrm{Hg}^{\mathrm{P}}$ versus $j \mathrm{NO}_{2}$ at $\mathrm{AI}$ (marine) in summer. Only daytime data were used.

\subsection{Temperature}

Examination of seasonal data of $\mathrm{Hg}^{0}$ versus temperature at $\mathrm{TF}$ (coastal) indicated a scattered, correlative relationship between $\mathrm{Hg}^{0}$ and temperature in all summers during the time period of 2004-2010 (Fig. 7) whereas no correlation appeared to exist in other seasons. The $r^{2}$ value varied over the range of $0.12-0.20$ with slope values over $0.7-$ $2.0 \mathrm{ppqv}^{\circ} \mathrm{C}^{-1}$. At $\mathrm{PM}$ (inland) the $\mathrm{Hg}^{0}$ versus temperature exhibited a somewhat positive correlation in springs 20072010 (Fig. 8). At AI (marine), no correlation between $\mathrm{Hg}^{0}$ and temperature was found for all seasons during 20072010. One curious exception is winter 2009 where we found a correlation of $r^{2}=0.2$ and a $1.2 \mathrm{ppqv}^{\circ} \mathrm{C}^{-1}$ slope value, and this correlation was not reproduced in the following winter.

In summary these relationships suggested a somewhat positive correlation between $\mathrm{Hg}^{0}$ and temperature in spring at a remote rural location situated above the boundary layer half of the time and in summer at a sea level coastal site, whereas no such correlation was found at a site in the marine boundary layer. The positive correlation at the former two sites was reproducible during the study period of 4-7 yr with slightly varying correlation coefficients and slope values, which indicates the consistency of the relationship.

The box plot of RGM versus temperature at TF (coastal), PM (inland), and AI (marine) suggested higher levels of RGM, be it the 25 th percentile, median, or 75 th percentile value, at warmer temperatures during the warm season (i.e., spring and summer) and this tendency was enhanced for daytime data (Fig. 9, PM not shown). At TF (coastal), in spring the majority of RGM mixing ratios $>2$ ppqv occurred at temperature $>9{ }^{\circ} \mathrm{C}$, and $10 \%$ of the daytime data in the highest temperature bin $\left(>18^{\circ} \mathrm{C}\right)$ had mixing ratios $>5 \mathrm{ppqv}$ (Fig. 9a). In summer, daytime data for temperatures $<21{ }^{\circ} \mathrm{C}$ had median levels below the LOD, and the median showed a distinct increase from around the LOD over the temperature bin $21-24^{\circ} \mathrm{C}$ to 0.3 ppqv for temperatures $>27^{\circ} \mathrm{C}$ (Fig. 9b). Wintertime data showed no discernible pattern; in the fall, median values were below the LOD in all temperature bins except the highest one $\left(>18^{\circ} \mathrm{C}\right)$ where it barely reached the LOD.

Similar to TF (coastal), larger RGM levels corresponded to higher temperatures in the marine boundary layer based on measurements at AI (marine), and this relationship was enhanced in daytime data (Fig. 9c, d). In fall, only in the highest temperature bin $\left(>16^{\circ} \mathrm{C}\right)$ did the median level of $\sim 0.3 \mathrm{ppqv}$ 


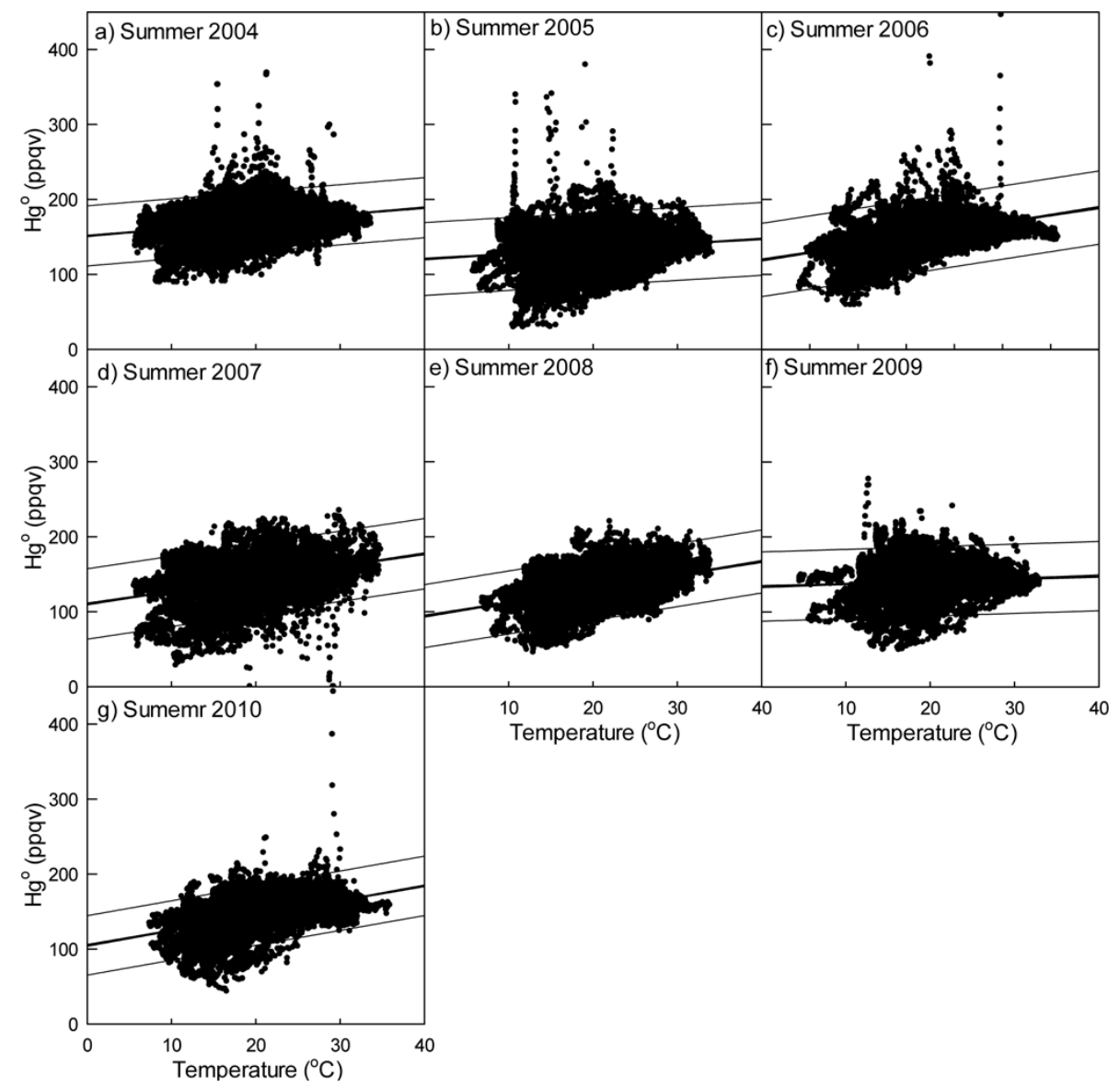

Fig. 7. Mixing ratios of $\mathrm{Hg}^{0}$ versus temperature in summers of 2004-2010 at TF (coastal).

exceed the LOD, and there was no systematic pattern in the 75th percentile value. One unique feature at AI (marine) was that in winter higher median values $(0.2-0.3 \mathrm{ppqv})$ were found in the temperature bins $-6-0^{\circ} \mathrm{C}$ while hovering around the LOD in temperature bins below $-6^{\circ} \mathrm{C}$ or above $0^{\circ} \mathrm{C}$ (Fig. 9e). This pattern was slightly enhanced in the daytime and lessened at night. Close examination revealed that $68 \%$ of the wintertime RGM samples below the LOD were collected in February 2010, which was ranked as the 13th warmest and 13th wettest February in New Hampshire based on the $116 \mathrm{yr}$ of record running from 1895 to 2010 (http: //www.nrcc.cornell.edu/page_summaries.html). This implies that more RGM was possibly washed out by rain water, as opposed to snow, in a warm winter season such as 2010 . More wintertime data in the future is needed to verify this hypothesis.

At PM (inland) the median and even the 75th percentile values rarely exceeded the LOD and thus the box plot of RGM vs. temperature at PM is not shown. However, there were two exceptions: (1) in spring the median barely reached the LOD and the 75th percentile values rose to $0.3-0.4 \mathrm{ppqv}$ as temperature went beyond $8^{\circ} \mathrm{C}$, and (2) in winter the 75 th percentile value varied over $0.1-0.2 \mathrm{ppqv}$ in all temperature bins with an increasing tendency at warmer temperatures.

Relationships between $\mathrm{Hg}^{\mathrm{P}}$ and temperature were examined for TF (coastal) and AI (marine) where measurements were available. At TF (coastal) total measurement data showed two opposite regimes in the $\mathrm{Hg}^{\mathrm{P}}$-temperature relationship: negative and positive correlation at temperatures below and above $8^{\circ} \mathrm{C}$, respectively (Fig. 10a). Similar to $\mathrm{RGM}, \mathrm{Hg}^{\mathrm{P}}$ exhibited an increasing tendency with warming temperatures in spring and summer, especially during daytime at TF (coastal) (Fig. 10b, c), which was consistently evidenced in the tendency of nearly all of the median, 75th, and 90th percentile values. The magnitude of such tendency was an increase of $\sim 0.3 \mathrm{ppqv}$ from the lower to upper end of temperature range (about $15{ }^{\circ} \mathrm{C}$ difference). In winter the tendency was reversed with the highest median and 75th values corresponding to the lower temperatures $\left(<-6^{\circ} \mathrm{C}\right)$ (Fig. 10d), and this tendency was enhanced in the nighttime data. The decrease in median and 75 th percentile values was around $0.7 \mathrm{ppqv}$ from $<-8^{\circ} \mathrm{C}$ to $>2{ }^{\circ} \mathrm{C}$ of temperature. In the fall, the median and 75 th percentile values over all temperature bins hovered around the LOD except at the upper end of the temperature range $\left(>17^{\circ} \mathrm{C}\right)$ with $\mathrm{Hg}^{\mathrm{P}}$ 


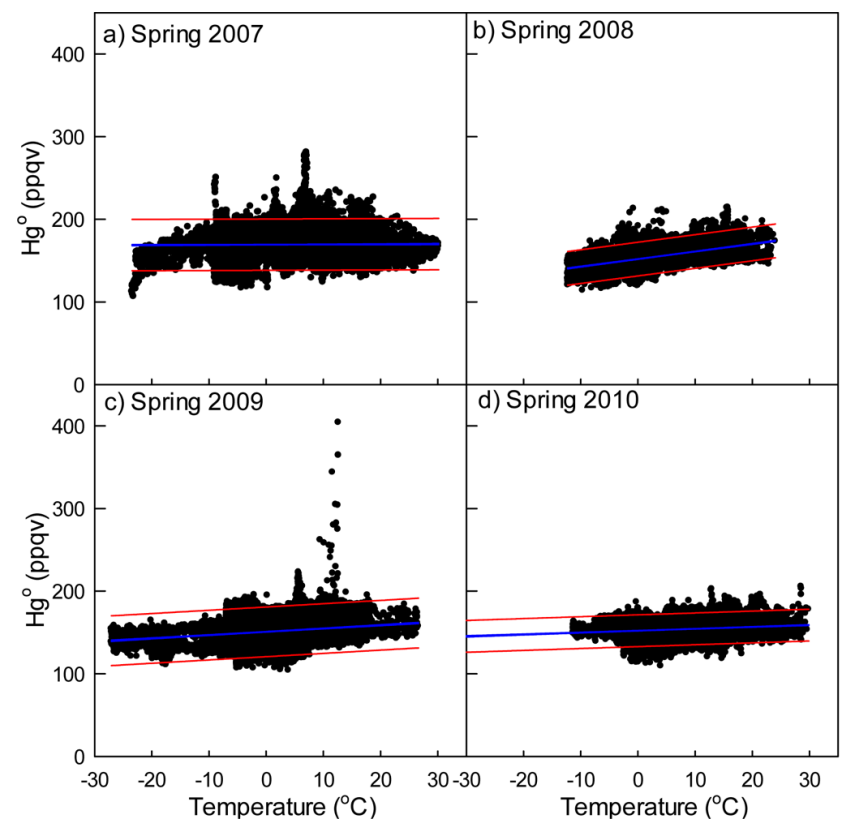

Fig. 8. Mixing ratios of $\mathrm{Hg}^{0}$ versus temperature in springs 20072010 at PM (inland).

reaching $0.3-0.4$ ppqv which occurred mostly close in time to the warm season.

At AI (marine), the $\mathrm{Hg}^{\mathrm{P}}$ versus temperature relationship for all data largely represents the relationship in spring, summer and fall, as there was only one month of data for the winter season during the study period. Temperature ranged from $<6^{\circ} \mathrm{C}$ to $>21^{\circ} \mathrm{C}$, much narrower than at TF (coastal), due in part to the marine climate. Perhaps because of the missing wintertime data, there is only one pattern showing in all metrics, which is that the 10th, 25th, median, 75th, and 90th percentile values increased with warming temperature (Fig. 11a). This tendency was enhanced in spring and summer (Fig. 11b, c). In the fall, the median values exceeded the LOD at temperatures $<10^{\circ} \mathrm{C}$ and temperatures $>16^{\circ} \mathrm{C}$; the latter was primarily close in time to the warm season (Fig. 11d).

\subsection{Relative humidity}

No overall correlation was observed between $\mathrm{Hg}^{0}$ and relative humidity at TF (coastal), PM (inland), and AI (marine) for all seasons. Three points are noted. First, at TF (coastal), in summer and fall there were very low levels of $\mathrm{Hg}^{0}$, reaching as low as 40-50 ppqv corresponding to 95-100\% relative humidity, which occurred on nights with nocturnal inversions. Second, in summer at AI (marine) there appeared to a linear upper boundary enveloping the data, which was reproduced in the three summers $(2007,2008$, and 2010) with available relative humidity data (Fig. 12a, b, c). Third, a 100 ppqv spread was observed at $\mathrm{RH}=100 \%$ and a 10 ppqv spread at $\mathrm{RH}=40 \%$ (Fig. $12 \mathrm{a}, \mathrm{b}, \mathrm{c}$ ).
However a close inspection of the upper boundary in the summertime data at AI (marine) (Fig. 12a-c) showed that nearly all the samples forming the linear upper boundaries were collected in the month of August during those three summers. Specifically, August data comprised $93 \%$ of the data forming the upper boundary, and these data points did not suggest preferential time quadrants of the day. Corresponding to these data points, there was a vague anticorrelation between $\mathrm{Hg}^{0}$ and temperature as well as between temperature and relative humidity (Fig. 12d, e, f, g). In the meantime no systematic patterns were observed between $\mathrm{Hg}^{0}$ and $j \mathrm{NO}_{2}$, as well as between $j \mathrm{NO}_{2}$ and temperature. Solar radiation may not be the dominant driving force for the linear relationship between $\mathrm{Hg}^{0}$ and relative humidity in August; it may result from the dominance of thermal processes in the marine boundary layer during that time of a year. Future research is warranted to understand the driving mechanism for this curious linearity in August.

Relationships between RGM and relative humidity at TF (coastal) suggested a clear decreasing tendency in all metrics, including 10 th, 25 th, median, 75 th, and 90th percentile values, from less than $40 \%$ to $100 \%$ relative humidity levels in all seasons (Fig. 13a-e). Particularly in spring, the median level of RGM was 1 ppqv, 75th and 90th percentile values were nearly 2 and 4 ppqv respectively for relative humidity $<40 \%$, followed by a steep decrease over the 50-60\% range and a continuous decrease to a median level below the LOD over the 90-100\% range. Similar patterns were found in all other seasons. At PM (inland), only in spring and winter for relative humidity below $60 \%$ the median level of RGM exceeded the LOD.

The largest difference in RGM versus relative humidity at AI (marine) (Fig. 13f-j) compared to TF (coastal) and PM (inland) was less variability of the metrics, except the 90th percentile value, over all bins of relative humidity. In the overall relationship (Fig. 13f) the 25 th, median, and 75 th percentile values varied over a narrow range of $0.17-0.36 \mathrm{ppqv}$ except the $90-100 \%$ bin where the median was below the LOD. Another difference was the highest levels of RGM, represented in metrics, were observed in summer for relative humidity $<50 \%$ compared to the highest levels of RGM occurring in spring at TF (coastal).

A close examination of the point-to-point corresponding plots of RGM versus relative humidity suggested that for TF (coastal) a better defined negative correlation occurred in spring and summer $\left(r^{2}=0.25\right.$ and 0.30 , respectively) than in fall and winter (Fig. 14). For AI (marine), RGM was correlated better in spring than in other seasons (not shown), although the correlation was more scattered compared to that at TF (coastal), possibly due to smaller variability in relative humidity in a marine environment than over land.

The relationship between higher levels of RGM and relative humidity at the two sites was looked into in detail. A threshold of 2 ppqv was used to select samples of higher RGM, because the maximum 90th percentile value of all 

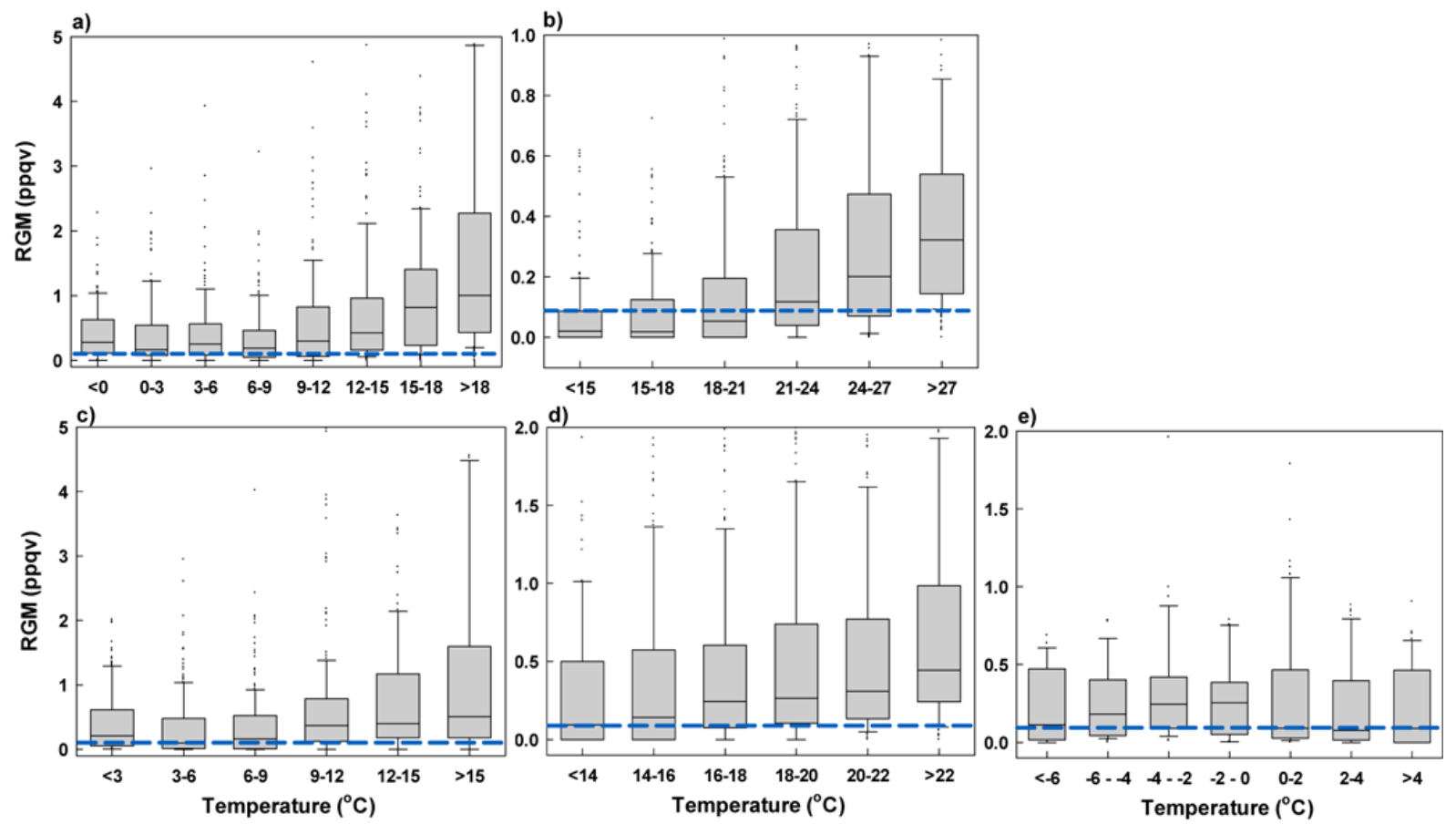

Fig. 9. Daytime mixing ratios of RGM versus temperature at TF (coastal) in (a) springs and (b) summers 2003-2010, at AI (marine) in (c) springs, (d) summers, and (e) winters 2007-2010. The blue dash lines mark the LOD (0.1 ppqv).
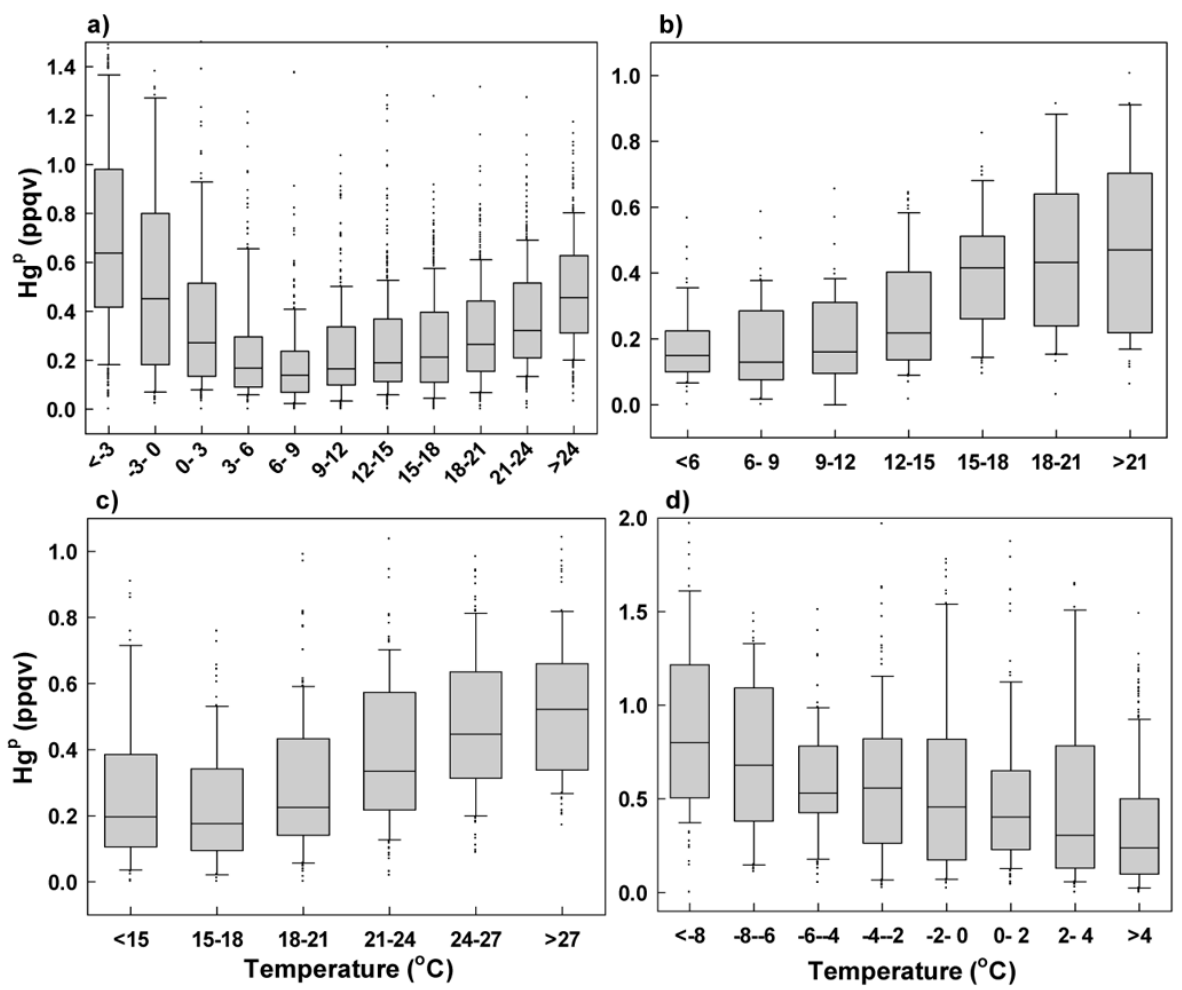

Fig. 10. Relationships between $\mathrm{Hg}^{\mathrm{P}}$ and temperature at $\mathrm{TF}$ (coastal) for (a) all seasons, (b) daytime springs, (c) daytime summers, and (d) winters during January 2009-August 2010. 

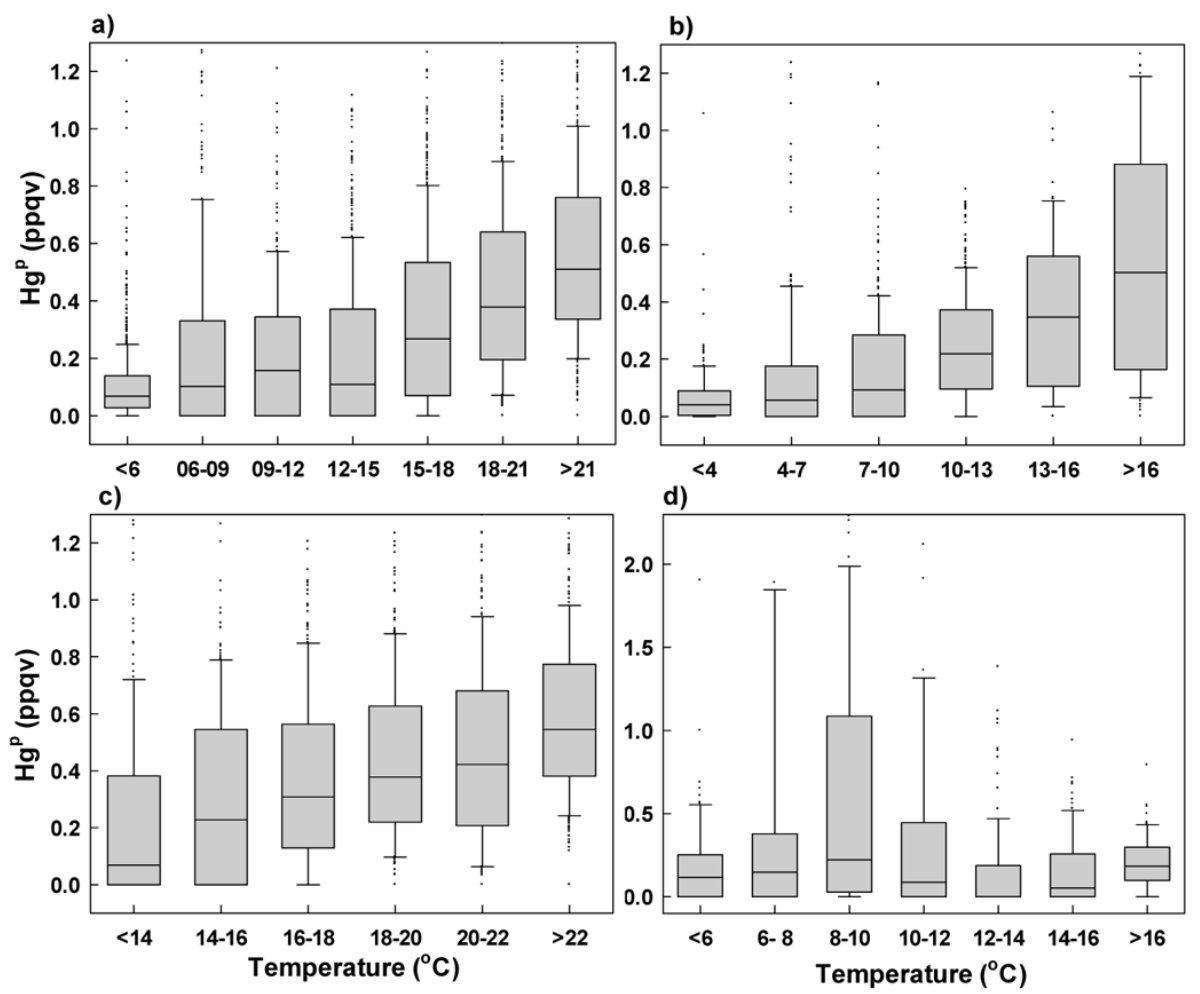

Fig. 11. Relationships between $\mathrm{Hg}^{\mathrm{P}}$ and temperature at $\mathrm{AI}$ (marine) for (a) all seasons, (b) springs, (c) summers, and (d) falls during April 2009-August 2010. There was only one month data for the winter season during the entire study period.

seasons was $1.9 \mathrm{ppqv}$ at $\mathrm{AI}$ (marine) and a bit lower at $\mathrm{TF}$ (coastal) (with only one exception in spring 2007); thus RGM mixing ratios exceeding 2 ppqv can be considered anomalously large for both locations. Since at night humidity reaches $>90 \%$ most of the time and removal of RGM and $\mathrm{Hg}^{\mathrm{P}}$ is rapid, we will consider the relationship for daytime only (i.e., 12:00-23:59 UTC) and no precipitation.

It was found that in spring higher RGM tended to occur under drier conditions at both sites whereas in summer was observed with no dependence on relative humidity at AI (marine). Specifically, at TF (coastal) $15 \%$ of the total 1336 samples exceeded 2 ppqv corresponding to relative humidity $<60 \%$ at TF (coastal) with half from 16:00-20:00 UTC, and at AI (marine) $\sim 10 \%$ of the total 542 points exceeded 2 ppqv occurring during 14:00-23:59 UTC with relative humidity $<70 \%$. In summers, hardly any samples exceeded 2 ppqv at TF (coastal), whereas at AI, a total of 48 data points were found with mixing ratios $>2$ ppqv and $\sim 90 \%$ of them (42 out of 48) in the time window of 12:00-14:00 UT with relative humidity varying over $40-100 \%$.

There seems to be no relationship between relative humidity and $\mathrm{Hg}^{\mathrm{P}}$ mixing ratios for all seasons at $\mathrm{AI}$ (marine). At TF (coastal) a correlation was observed for summers 2009 and 2010 with $r^{2}=0.38$ and 0.29 respectively and slope val-

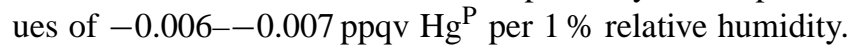
The reason for this relationship is unclear.

\subsection{Precipitation}

Effects of precipitation on RGM and $\mathrm{Hg}^{\mathrm{P}}$ at $\mathrm{TF}$ (coastal) and $\mathrm{AI}$ (marine) were examined for all seasons. The seasonal averages $( \pm 1 \sigma)$ for RGM at TF (coastal) under rainy and dry conditions are summarized in Table 1 . Note that precipitation data are not available at PM (inland), and thus PM is not considered. In the four summers of 2007-2010, the average levels of RGM under dry conditions varied from 0.1 to $0.2 \mathrm{ppqv}$, whereas more than $95 \%$ of the samples under rainy conditions were below the LOD except summer 2009. In summer 2009 a little over half of the data points from rainy conditions were below the LOD, and therefore that was the only summer with the average RGM level barely above the LOD. Similarly in all four falls the majority of RGM mixing ratios $(>80 \%)$ were below the LOD under rainy conditions. In spring and winter RGM mixing ratios more likely remained above the LOD during rainfalls. In springs of 2007-2010 seasonal averages under rainy conditions varied around 0.2 ppqv with less than half of the samples below the LOD and those under dry conditions were a factor of 3-4 to two orders of magnitude higher, suggesting that the RGM production rate dominated over the washout effect of precipitation in spring. In winters of 2007-2010, only snowfalls were considered, and three-hourly accumulated precipitation from snowfalls hardly exceeded $10 \mathrm{~mm}$, none in winter 

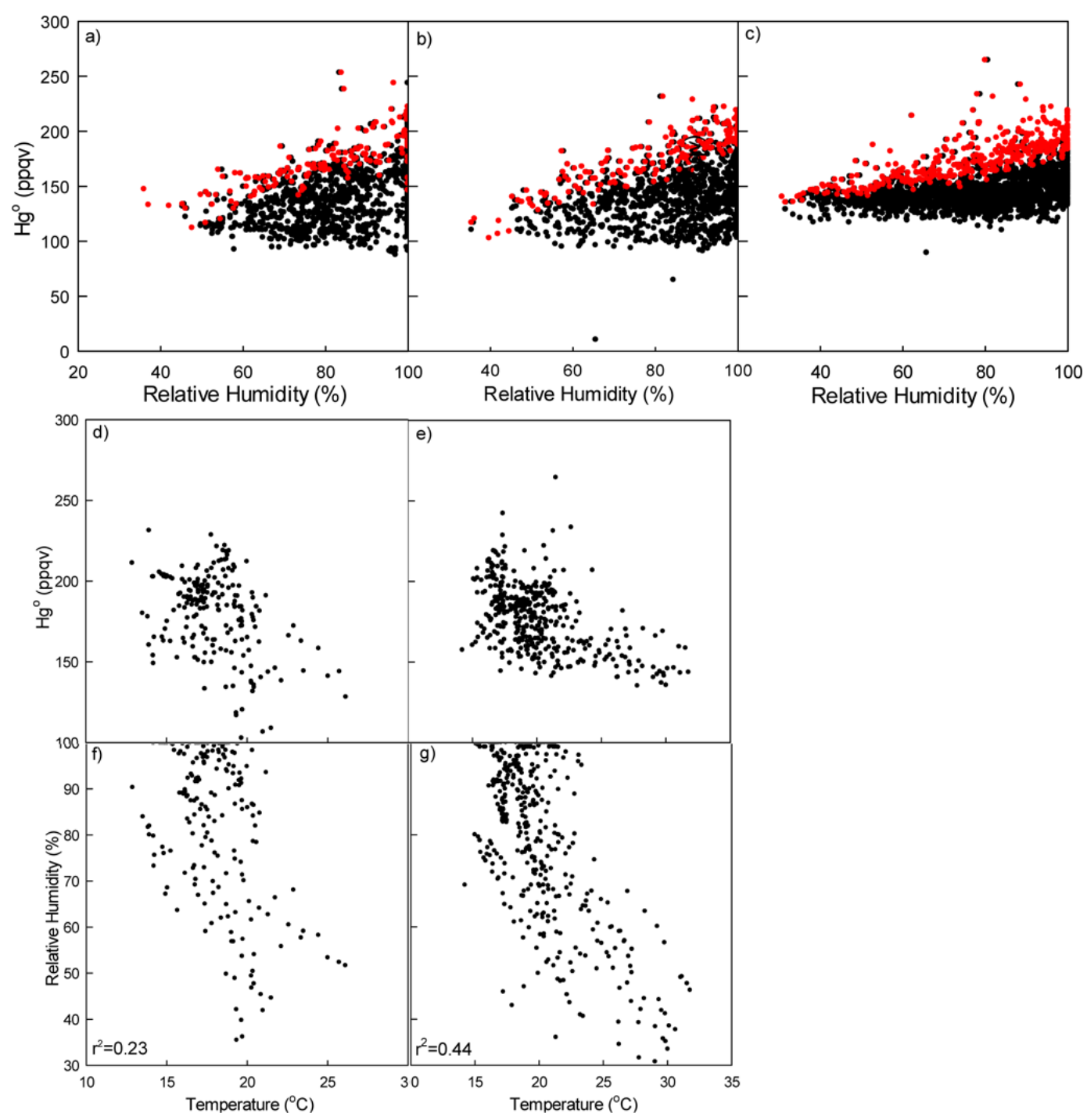

Fig. 12. Relationships between $\mathrm{Hg}^{0}$ and relative humidity at $\mathrm{AI}$ (marine) for summers (a) 2007, (b) 2008, and (c) 2010. Points forming the linear upper boundary are highlighted in red. Relationships between $\mathrm{Hg}^{0}$ and temperature (d, e), temperature and relative humidity (f, $\left.\mathbf{g}\right)$ for the points in the upper boundary in summers 2008 and 2010.

2010. In contrast to summer, RGM mixing ratios appeared to be mostly above the LOD during snowfalls at $0.14 \pm 0.20$, $0.18 \pm 0.33,0.45 \pm 0.23$, and $0.14 \pm 0.21 \mathrm{ppqv}$ for the 2007 2010 winters.

Further examination of RGM at TF (coastal) separated the data into three subsets: days without rain (i.e., dry), with nighttime rain, and with daytime rain. Diurnal cycles were averaged seasonally each year for each subset (Fig. 15). Five main characteristics are summarized here. First, the diurnal cycle on dry days was well-defined with minimum values before sunrise and peaks over 15:00-17:00 UTC, and the annual maximum daily amplitude (daily maximum-minimum) occurred in spring varying from 0.8 ppqv in 2010 to $1.8 \mathrm{ppqv}$ in 2007. Second, in contrast to the dry days, the diurnal variation was dampened greatly on days with nighttime rain, e.g., a daily amplitude of 0.3 ppqv in spring 2010 and 0.7 ppqv in spring 2007, and there was little to no variability on days with daytime rain. In other words, even if it rained before sunrise and it was dry during the daytime, the daily peak did not go back to the levels of dry days. This suggests that RGM in the residual layer was washed out at night leading to less contribution to the surface level of RGM via downward mixing from aloft after sunrise. Third, for springtime dry days, the daytime RGM mixing ratios were the largest of all seasons and under all conditions with discernible year-to-year fluctuations in the daily maximum, varying from $1 \mathrm{ppqv}$ in spring 2010 to 2.3 ppqv in spring 2007. Fourth, for dry days the magnitude and pattern of diurnal variation appeared to be similar between summer and fall, although there seemed to be larger year-to-year variability in daytime RGM levels 

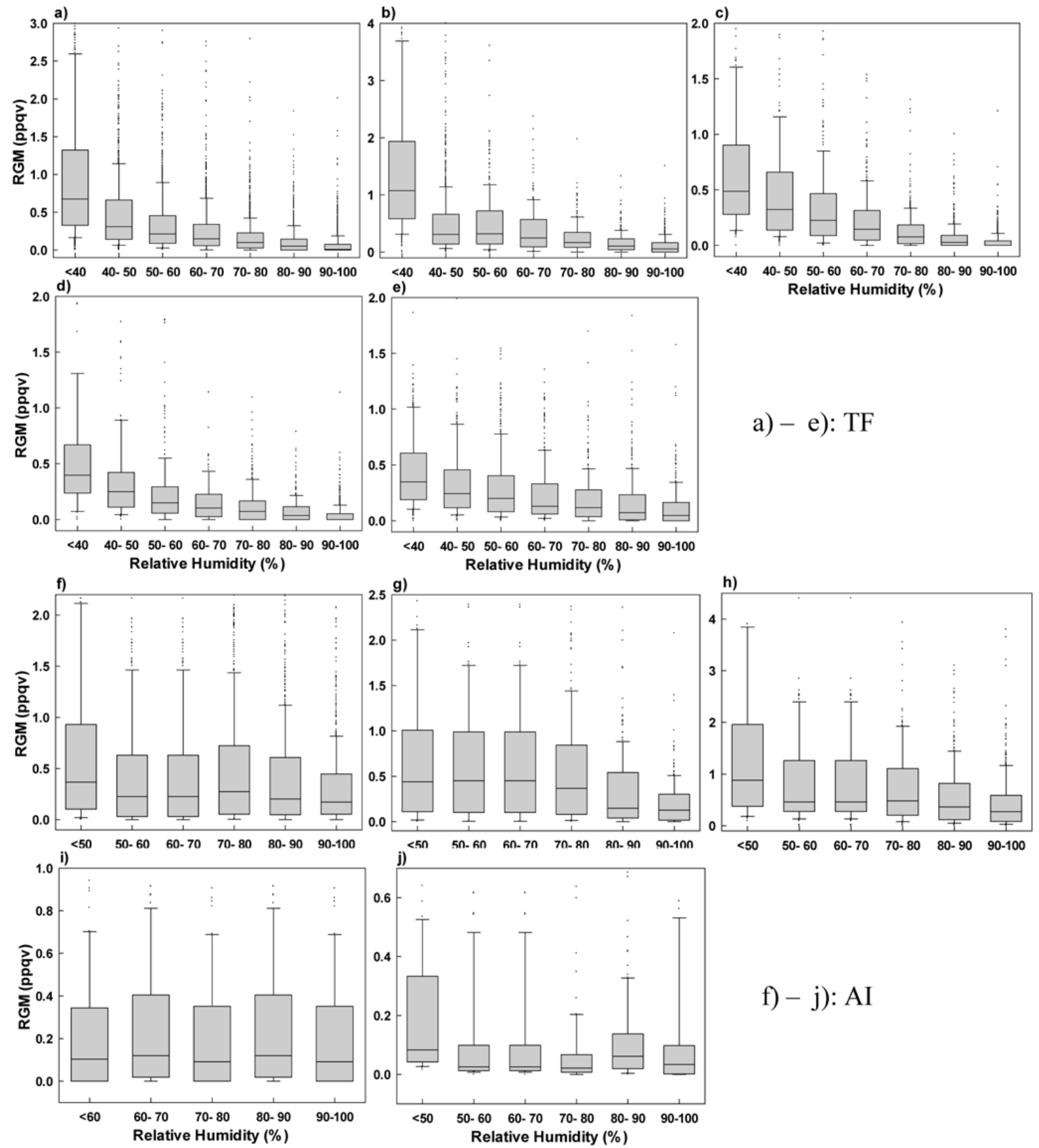

a) - e): TF

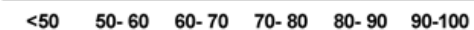

\section{f) $-\mathrm{j}): \mathrm{AI}$}

Fig. 13. Relationships between RGM and relative humidity at TF (coastal) (a-e) and AI (marine) (f-j) for all seasons (a, f), springs (b, g), summers (c, h), falls $(\mathbf{d}, \mathbf{i})$, and winters $(\mathbf{e}, \mathbf{j})$.

in the fall. Fifth, nighttime RGM levels in winter, be it dry or wet, were lower than those in spring but higher than in summer and fall.

Closer examination of changes in RGM at the onset of and during rainfalls in summer and spring at TF (coastal) revealed two main characteristics. First, the RGM levels generally fell below the LOD immediately after a rainfall began nearly independent of the precipitation amount. Second, there were 12 exceptional events, mostly in spring and summer, where RGM actually increased during a rainfall, and there were four rainfalls lasting 9-19 $\mathrm{h}$ with RGM mixing ratios consistently hovering at levels above the LOD (Table 2).

Diurnal and seasonal variability in $\mathrm{Hg}^{\mathrm{P}}$ at TF (coastal) appeared to be smaller than that of RGM at TF (coastal) in the three subsets of data (Fig. 16). On dry days, the magnitude of $\mathrm{Hg}^{\mathrm{P}}$ variability in spring was close to that in winter, with 

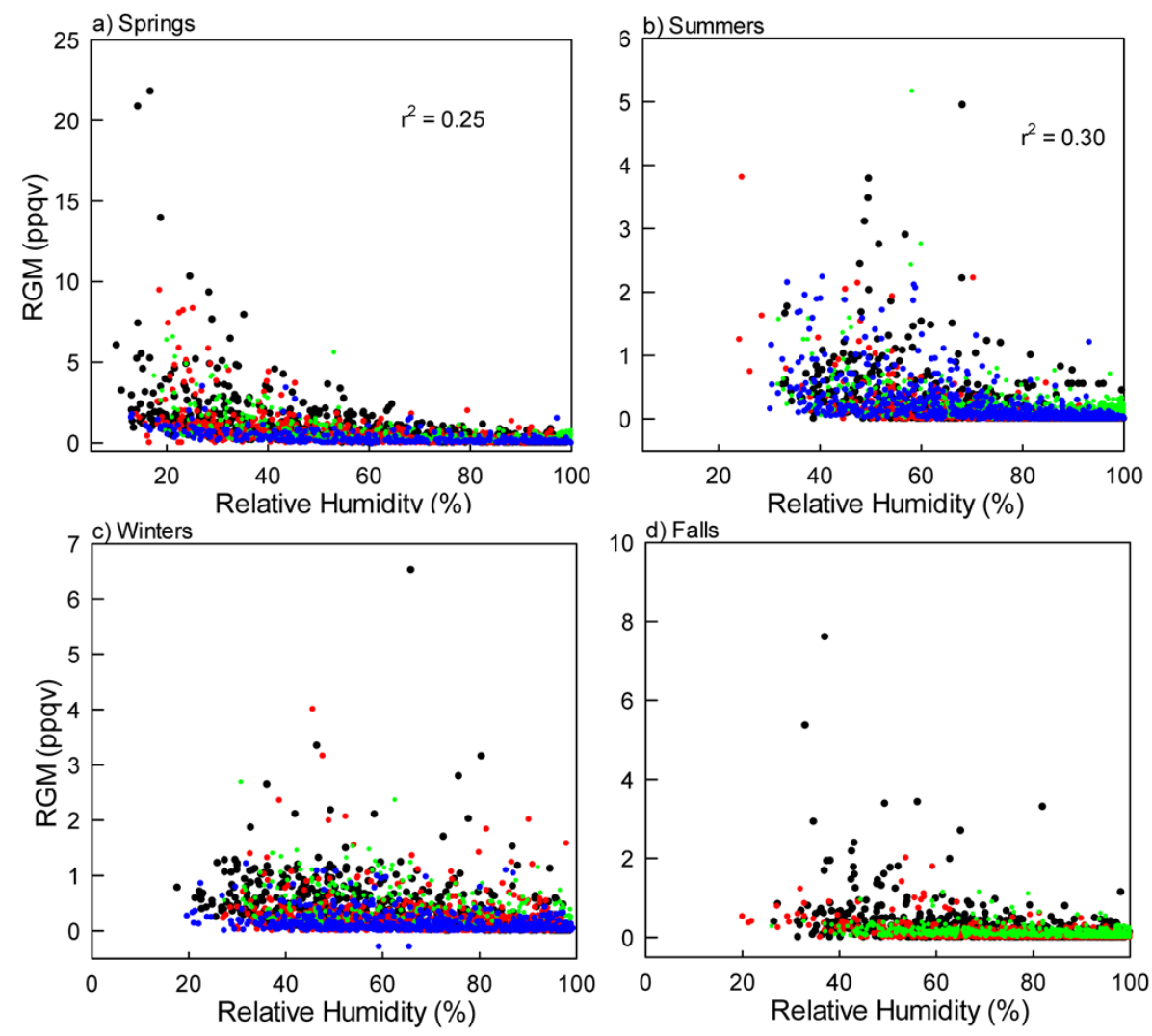

Fig. 14. Relationships between RGM and relative humidity at TF (coastal) in (a) springs, (b) summers, (c) falls, and (d) winters with data from 2007 in black, 2008 in red, 2009 in green and 2010 in blue.

both hovering around $0.5 \mathrm{ppqv}$ compared to mostly below $0.5 \mathrm{ppqv}$ in summer and fall. The diurnal variability and patterns on days with nighttime and daytime rain did not differ from those on dry days as much as RGM, meaning $\mathrm{Hg}^{\mathrm{P}}$ was rarely washed out entirely by precipitation and most samples remained above the LOD. A few sample points of $\mathrm{Hg}^{\mathrm{P}}$ below the LOD were found during snowfalls: (1) when a snowfall started at night and lasted throughout the night, or (2) when rain preceded the snowfall, and likely reduced the $\mathrm{Hg}^{\mathrm{P}}$ mixing ratio substantially before the snow began.

For AI (marine) we used 6-hourly precipitation data, which is different from the hourly time resolution for TF (coastal). This is because the only available precipitation data for AI are the 6-hourly data from the National Weather Service monitoring site at the Pease Airport, about $10 \mathrm{~km}$ from AI. To match that, we integrated RGM over the 6-h interval. Without hourly precipitation data it is impossible to examine in detail the effects of precipitation on RGM; therefore, we can only report the general features observed in the 6-hourly averaged data. At AI (marine) under dry conditions, seasonally averaged mixing ratios remained well above the LOD in all seasons with remarkable year-to-year variability (Table 3). For example, in spring the average was lowest in 2010 at $0.37 \mathrm{ppqv}$ and highest in 2008 at $0.89 \mathrm{ppqv}$, and in fall the lowest average was found to be $0.26 \mathrm{ppqv}$ in 2008 and highest 0.59 ppqv in 2009.

Furthermore, similar to TF (coastal), under dry conditions the seasonally averaged diurnal patterns of RGM at AI (marine) were better defined in spring and summer than fall and winter (Fig. 17). Overall nighttime and daytime precipitation dampened diurnal variability lowering RGM levels throughout the day except in winter when nighttime precipitation suppressed mixing ratios only during the nighttime and conversely daytime precipitation only lowered the daytime mixing ratios. Summer 2007 and fall 2009 appeared to be quite different with much higher mixing ratios on days when nighttime or daytime precipitation occurred. A closer look revealed that the RGM mixing ratio was only slightly decreased by precipitation events in summer 2007, and in fall 2009 there were $\sim 10$ days over 21 October-1 November when particularly strong precipitation events were accompanied by unusually high levels of RGM. A preliminary examination of limited chemical tracers (only $\mathrm{CO}$ and $\mathrm{O}_{3}$ were available) and trajectories did not suggest any particularly dominant mechanisms driving the unusual behavior in RGM during those two seasons (Mao et al., 2012).

There were three distinct characteristics of the impacts of precipitation on $\mathrm{Hg}^{\mathrm{P}}$ at $\mathrm{AI}$ (marine): (1) seasonal averaged 
Table 1. Seasonal mean (denoted as avg) $\pm 1 \sigma$ values (ppqv) of RGM at Thompson Farm for rainy and dry conditions. $N$ stands for the number of samples. $N_{\mathrm{b}}$ stands for the number of samples with RGM below the LOD.

\begin{tabular}{llllll}
\hline & \multicolumn{4}{c}{ Rainy } & dry \\
\cline { 2 - 6 } & $N$ & $N_{\mathrm{b}}$ & $\operatorname{Avg} \pm 1 \sigma$ & $N$ & $\operatorname{Avg} \pm 1 \sigma$ \\
\hline Spring 2007 & 118 & 59 & $0.19 \pm 0.32$ & 900 & $0.99 \pm 1.68$ \\
2008 & 111 & 48 & $0.19 \pm 0.25$ & 905 & $0.59 \pm 1.18$ \\
2009 & 95 & 34 & $0.26 \pm 0.23$ & 562 & $0.75 \pm 0.90$ \\
2010 & 94 & 56 & $0.01 \pm 0.18$ & 506 & $0.38 \pm 0.56$ \\
\hline Summer 2007 & 71 & 69 & $0.01 \pm 0.03$ & 1020 & $0.21 \pm 0.50$ \\
2008 & 85 & 81 & $0.02 \pm 0.05$ & 894 & $0.11 \pm 0.33$ \\
2009 & 106 & 58 & $0.11 \pm 0.09$ & 580 & $0.20 \pm 0.36$ \\
2010 & 58 & 56 & $0.03 \pm 0.03$ & 651 & $0.21 \pm 0.36$ \\
\hline Fall 2006 & 47 & 44 & $0.03 \pm 0.05$ & 229 & $0.16 \pm 0.39$ \\
2007 & 93 & 77 & $0.07 \pm 0.15$ & 935 & $0.25 \pm 0.59$ \\
2008 & 99 & 88 & $0.03 \pm 0.06$ & 748 & $0.09 \pm 0.23$ \\
2009 & 48 & 33 & $0.11 \pm 0.12$ & 431 & $0.13 \pm 0.16$ \\
\hline Winter 2007 & 79 & 45 & $0.14 \pm 0.20$ & 947 & $0.37 \pm 0.50$ \\
2008 & 164 & 90 & $0.18 \pm 0.32$ & 863 & $0.22 \pm 0.42$ \\
2009 & 20 & 0 & $0.46 \pm 0.23$ & 200 & $0.53 \pm 0.39$ \\
2010 & 58 & 34 & $0.14 \pm 0.21$ & 402 & $0.14 \pm 0.19$ \\
\hline
\end{tabular}

mixing ratios hovered around the LOD under rainy conditions in all seasons, (2) highest seasonal averaged levels under dry condition occurred in fall and summer and lowest in winter, and (3) compared to RGM, there appeared to be smaller variability in seasonal average levels for both rainy and dry conditions (Table 4). The three subsets of $\mathrm{Hg}^{\mathrm{P}}$ data, i.e., dry, with nighttime rain, and with daytime rain, suggested that occurrence of rain, be it at night or during the day, had negligible impact on the magnitude and pattern of diurnal variation of $\mathrm{Hg}^{\mathrm{P}}$ at $\mathrm{AI}$ (marine) in all seasons (Fig. 18). Moreover, there was little variability in the four seasons under the three conditions, except in fall 2009 which was a unique case.

\section{Discussion}

To the best of our knowledge, our study is the first attempt to examine aforementioned relationships using long-term continuous measurement data of highest temporal resolution for different seasons and contrasting geographical environments. We found that one-to-one corresponding relationships between speciated mercury and physical parameters of high temporal resolution were too scattered to yield meaningful correlations except $\mathrm{Hg}^{0}$ vs. temperature at TF (coastal) and PM (inland) during the warm season. However, subsets of data disclosed correlations in large part due to the dominance of a single parameter in the processes. This point is illustrated in Fig. 1c, which suggested a linear correlation between $\mathrm{Hg}^{0}$ and wind speed from a strong storm event over Appledore Is- land, when the strong wind was likely the dominant drive of enhanced $\mathrm{Hg}^{0}$ levels due to possible evasion from the ocean. Another example is the positive correlation between relative humidity and $\mathrm{Hg}^{0}$ during the month of August (highlighted in red in Fig. 12), indicating a common dominant mechanism controlling relative humidity and $\mathrm{Hg}^{0}$ levels during that time period. Further, tendencies of speciated mercury with respect to changes of individual physical parameters were revealed when their magnitude ranges were discretized into small bins. In this section key findings are summarized in Table 5 and are discussed in comparison to previous works. Note in Table 5 a physical or chemical mechanism (such as transport or production) was provided when it could be speculated with the support of logic and evidence that were available from this study; otherwise, description of a result was given.

\subsection{Wind}

Effects of wind on ambient levels of speciated mercury had been demonstrated to mainly facilitate transport from upwind sources by examining the wind rose of mercury concentrations and backward trajectories of mercury rich air masses (e.g., Poissant et al., 2005; Gariel et al., 2005; Sigler et al., 2009a; Aucott et al., 2009) and to enhance mercury evasion (Gårdfeldt et al., 2003; Sigler et al., 2009b). Our study confirmed such effects of wind speed and direction on mercury. In particular, we revealed a somewhat positive correlation between $\mathrm{Hg}^{0}$ and wind speed with minimal anthropogenic influence indicative of oceanic origin during a major storm over 14-16 November 2008. This effect reached TF (coastal) and PM (inland) causing synchronized changes in $\mathrm{Hg}^{0}$ at all three sites. This finding corroborated our hypothesis in Sigler et al. (2009b) that strong wind induced enhancement in oceanic emissions of $\mathrm{Hg}^{0}$ can have a regional influence on ambient levels of $\mathrm{Hg}^{0}$ that can reach far inland.

At TF (coastal), higher RGM levels were speculated to possibly result from local production and transport. These higher levels nearly all occurred in the time window of 18:00-23:00 UTC when solar radiation was strongest. Transport of RGM to TF (coastal) was supported by the evidence that RGM $>3$ ppqv occurred in two ranges, southeasterly $\left(\sim 135^{\circ}\right)$ and southerly to northwesterly $\left(180-315^{\circ}\right)$, the flow regimes that facilitated pollutant transport from sources in the Northeast (Mao and Talbot, 2004b). Moreover, these relatively high RGM levels seemed to be associated with large $\mathrm{SO}_{2}$ mixing ratios indicating combustion sources, which will be further investigated in a separate manuscript on the relationships between mercury and key chemical compounds (Mao et al., 2012). As the wind speed increased past $3 \mathrm{~m} \mathrm{~s}^{-1}$, the median value appeared to level off while the 75th and 90th percentile values decreased (Fig. 4a). This implies opposing effects of windier conditions on the ambient level of RGM at TF (coastal), increased dry depositional loss and enhanced transport of RGM. The speculation on the negative 


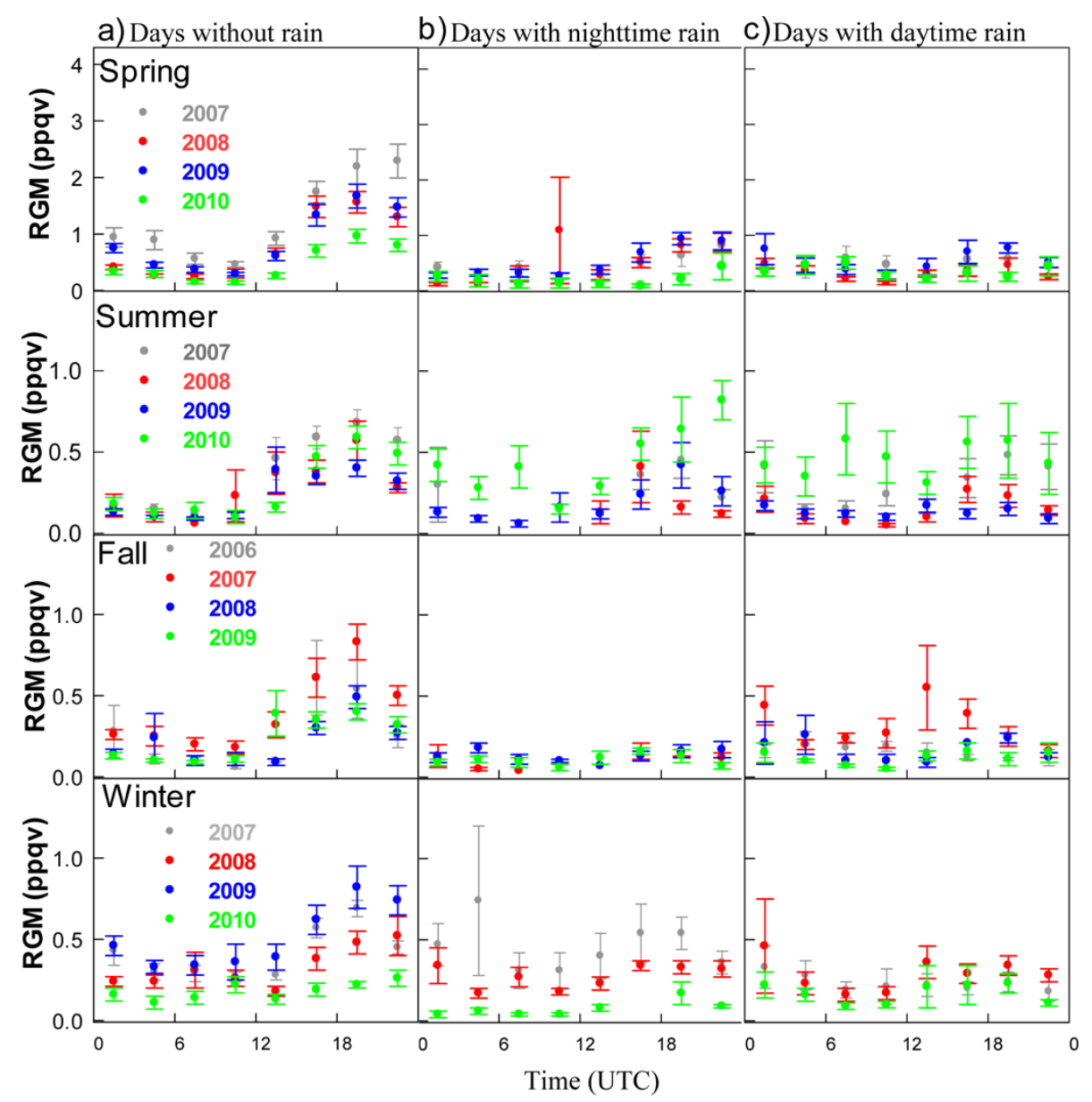

Fig. 15. Diurnal cycles of RGM at TF (coastal) averaged over days without rain (a), days with nighttime rain (b), and days with daytime rain (c) for all seasons during 2006-2010. It should be noted that there were data in February only in winter 2009 and there were too few data for conditions in (b) and (c) in winter to be presented for comparison. Similarly there were data in November only for fall 2006 and there were insufficient data in Fall 2006 for (b). Precipitation in winter includes rain and snow. Local nighttime is about 00:00-11:00 UTC, daytime 12:00-23:00 UTC, and noontime is 16:00 UTC during the Daylight Saving period of the year and 17:00 UTC otherwise.

effect of stronger winds on RGM via enhanced dry deposition is supported by Holmes et al. (2009) which showed the observed decline of RGM with increasing wind speed. In addition, stronger winds are often associated with precipitation resulting in scavenging via wet deposition. The effect of wind on dry deposition of RGM

In the marine environment at $\mathrm{AI}$, a few sample points with mixing ratios $>4$ ppqv occurred in spring mostly in the southerly to westerly wind directions, downwind of the greater Boston area and southern NH. It is curious that RGM could survive the transport over a distance of $4-5 \mathrm{~h}$, i.e., $\sim 80 \mathrm{~km}$, in the marine air laden with sea salt aerosols. It implies strong net production of RGM in transit, largely in the marine environment in addition to possible anthropogenic contributions. Further, it could also result from release of RGM in the form of $\mathrm{HgCl}_{2}$ from the surface of sea salt aerosols as suggested by Pirrone et al. (2000) and the several days of lifetime of sea salt aerosols. It should be noted that at wind speed $>10 \mathrm{~m} \mathrm{~s}^{-1}$, the median, 75th and 90th percentile mixing ratios of RGM dropped by nearly a factor of 2 indicating loss through deposition. Overall, RGM at AI seemed to be a result of $\mathrm{Hg}^{0}$ oxidation, transport, and deposition, of which the net effect seemed to be positive on the ambient level over the $<6 \mathrm{~m} \mathrm{~s}^{-1}$ wind speed range.

Previous research suggested the impact of wind on $\mathrm{Hg}^{\mathrm{P}}$ was manifested in the short- and long-range transport of $\mathrm{Hg}^{\mathrm{P}}$ from source regions to downwind areas (Ames et al., 1998; Rothenberg et al., 2010). Our study suggested different relationships between $\mathrm{Hg}^{\mathrm{P}}$ and wind speed in the coastal (TF) and marine (AI) environments. While no apparent dependence of $\mathrm{Hg}^{\mathrm{P}}$ on wind speed was observed at the coastal site (TF), a decreasing tendency in $\mathrm{Hg}^{\mathrm{P}}$ mixing ratios with increasing wind speed at AI (marine) suggested a strong impact of dry depositional loss of aerosols on ambient mixing ratios in the marine environment. Mixing ratios of $\mathrm{Hg}^{\mathrm{P}}$ over the 
Table 2. At TF (coastal) Rainfalls during which RGM levels (ppqv) were not washed out maintaining above the LOD together with precipitation amount $(\mathrm{mm})$ for each sample cycle. The rainfall episodes on the left saw increasing RGM levels, and the ones on the right had sustained RGM levels during rainfalls that lasted hours.

\begin{tabular}{|c|c|c|c|c|c|}
\hline & RGM & Rain & & RGM & Rain \\
\hline 3/15/2007 12:23:00 & 0.11 & 0.3 & 4/4/2007 23:22:00 & 0.25 & 4.2 \\
\hline 3/15/2007 14:23:00 & 0.25 & 0.8 & 2/19/2009 14:01:00 & 0.22 & 5.0 \\
\hline 3/15/2007 16:23:00 & 0.31 & 0.9 & 6/19/2009 00:51:00 & 0.34 & 2.2 \\
\hline 4/13/2007 00:18:00 & 0.00 & 4.5 & 6/19/2009 03:46:00 & 0.28 & 4.8 \\
\hline 4/13/2007 02:18:00 & 0.08 & 3.9 & 6/19/2009 06:41:00 & 0.30 & 9.6 \\
\hline 4/13/2007 04:18:00 & 0.29 & 0.4 & 6/19/2009 10:16:00 & 0.31 & 5.3 \\
\hline 4/15/2007 14:48:00 & 0.44 & 0.7 & 6/19/2009 13:11:00 & 0.31 & 1.7 \\
\hline 4/15/2007 16:48:00 & 0.38 & 5.7 & 6/19/2009 16:06:00 & 0.34 & 7.7 \\
\hline 4/15/2007 18:48:00 & 0.56 & 5.1 & 6/19/2009 19:01:00 & 0.32 & 2.1 \\
\hline 4/15/2007 20:48:00 & 0.42 & 4.4 & $6 / 21 / 2009$ 12:31:00 & 0.21 & 0.4 \\
\hline 4/15/2007 22:48:00 & 0.57 & 5.6 & $6 / 21 / 2009$ 15:26:00 & 0.20 & 0.5 \\
\hline 2/28/2008 05:37:00 & 0.00 & 0.6 & 6/21/2009 18:21:00 & 0.25 & 1.0 \\
\hline 2/28/2008 07:37:00 & 1.09 & 0.3 & 7/2/2009 09:26:00 & 0.21 & 0.4 \\
\hline 3/12/2008 17:27:00 & 0.14 & 1.5 & 7/2/2009 12:21:00 & 0.21 & 2.6 \\
\hline 3/12/2008 19:27:00 & 0.49 & 0.2 & 7/2/2009 15:16:00 & 0.21 & 15.9 \\
\hline 3/19/2008 06:02:00 & 0.19 & 0.2 & 7/2/2009 18:11:00 & 0.26 & 2.1 \\
\hline 3/19/2008 08:02:00 & 0.61 & 0.4 & $7 / 2 / 2009$ 21:06:00 & 0.22 & 6.0 \\
\hline 4/28/2008 20:32:00 & 0.13 & 8.8 & 7/3/2009 00:01:00 & 0.22 & 1.5 \\
\hline 4/28/2008 22:32:00 & 0.53 & 7.7 & 11/20/2009 11:22:00 & 0.27 & 0.5 \\
\hline 10/22/2008 01:52:00 & 0.04 & 0.6 & $3 / 13 / 2010$ 23:47:00 & 0.17 & 1.7 \\
\hline 10/22/2008 03:52:00 & 0.26 & 0.2 & 3/14/2010 03:22:00 & 0.20 & 3.9 \\
\hline 2/20/2009 03:01:00 & 0.47 & 0.9 & 3/14/2010 06:22:00 & 0.22 & 12.2 \\
\hline 2/20/2009 05:56:00 & 0.51 & 6.0 & 4/16/2010 12:27:00 & 0.26 & 0.4 \\
\hline 2/20/2009 08:51:00 & 1.14 & 1.4 & 4/16/2010 15:27:00 & 0.25 & 1.2 \\
\hline 5/7/2009 07:41:00 & 0.54 & 6.5 & 4/16/2010 18:27:00 & 0.33 & 1.7 \\
\hline $5 / 7 / 2009$ 10:36:00 & 0.54 & 10.2 & 4/16/2010 21:27:00 & 0.38 & 3.8 \\
\hline 5/7/2009 13:31:00 & 0.32 & 3.5 & 4/17/2010 00:27:00 & 0.26 & 1.1 \\
\hline 5/7/2009 16:26:00 & 0.28 & 0.3 & & & \\
\hline 10/7/2009 09:22:00 & 0.27 & 2.8 & & & \\
\hline 10/7/2009 17:22:00 & 0.63 & 1.1 & & & \\
\hline 10/7/2009 20:22:00 & 0.44 & 0.4 & & & \\
\hline 10/25/2009 04:52:00 & 0.24 & 3.1 & & & \\
\hline 10/25/2009 07:52:00 & 0.22 & 0.7 & & & \\
\hline
\end{tabular}

range of $0.5-1.5 \mathrm{ppqv}$ concurrent often with westerly flow indicates a land influence on the marine site.

\subsection{Solar radiation}

Consistent with previous studies (Mason and Sheu, 2002; Spovieri et al., 2003; Laurier et al., 2003; Engle et al., 2008; Sigler et al., 2009a), positive relationships were observed between solar radiation and $\mathrm{RGM}$ as well as $\mathrm{Hg}^{\mathrm{P}}$ at TF (coastal) and AI (marine) in the warm season. Furthermore, our results suggested seasonal difference between sites for RGM. A positive relationship between RGM and solar radiation was found in spring at TF (coastal), while in both spring and summer at AI (marine). Additionally the increase with radiation flux was more significant at the coastal compared to the marine site.

Such seasonal difference indicates that the solar radiation driven production processes controlling the ambient level of 


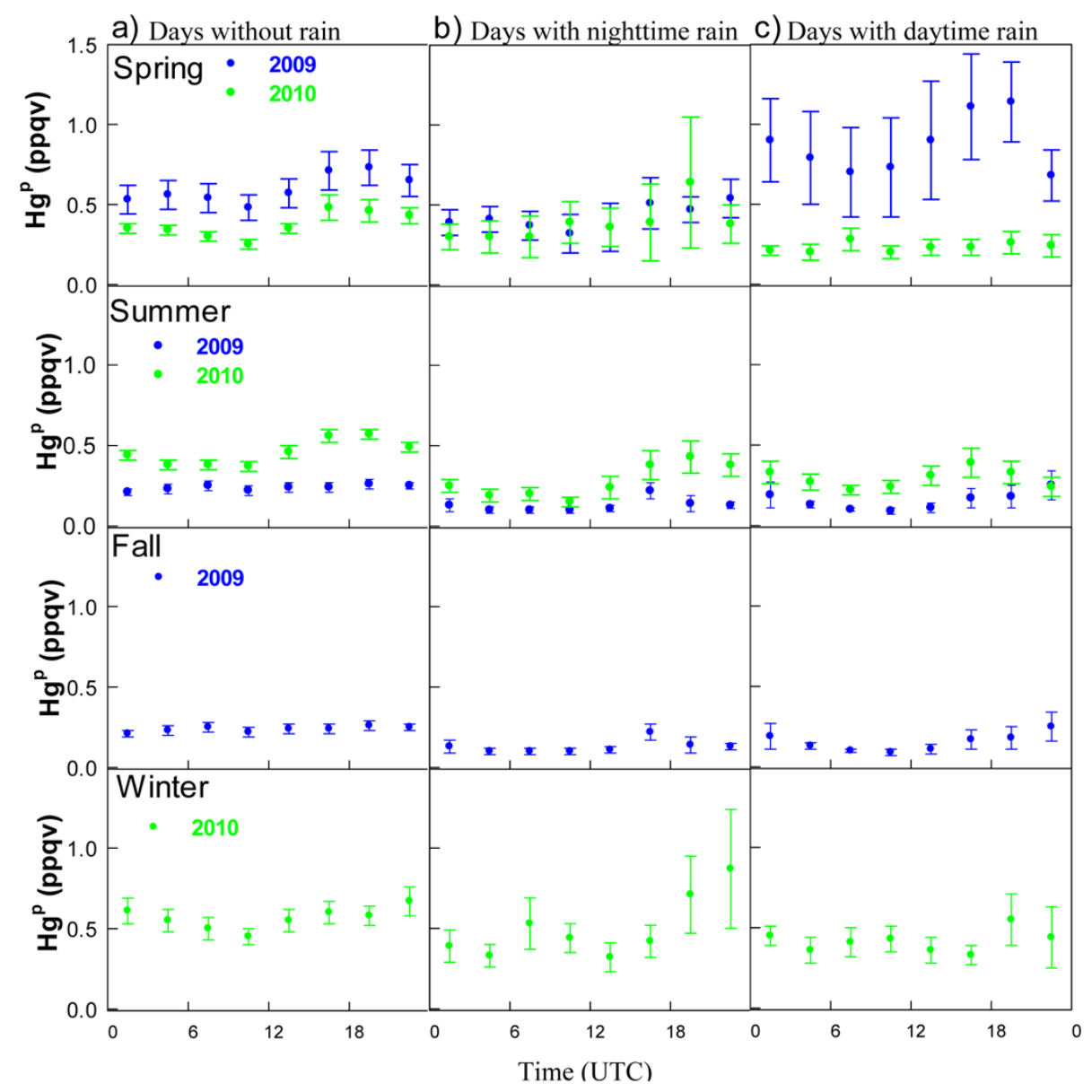

Fig. 16. Diurnal cycles of $\mathrm{Hg}^{\mathrm{P}}$ at $\mathrm{TF}$ (coastal) averaged over days without rain (a), days with nighttime rain (b), and days with daytime rain (c) for all seasons during 2009-2010. Precipitation in winter includes rain and snow. Local nighttime is about 00:00-11:00 UTC, daytime 12:00-23:00 UTC, and noontime is 16:00 UTC during the Daylight Saving period of the year and 17:00 UTC otherwise.

RGM were predominant in different seasons in the two environments. It is not clear what mechanisms contributed to such seasonal difference between the two sites. Compared to the coastal environment more factors can affect RGM production in the marine environment in addition to solar radiation, including halogen radical concentrations and sea salt aerosol concentrations. The seasonal and diurnal variabilities in these factors may not be synchronized and thus different combinations of factors may weigh in on their influences on RGM production at different times. Halogen radical concentrations are dependent on solar radiation, which is indirectly supported by observed halocarbons reaching annual minimum in summer due to faster photodissociation (Zhou et al., 2008) conducive to higher levels of halogen radical concentrations. This may explain why the effect of solar radiation on RGM was observed in both spring and summer at the marine site.

\subsection{Temperature}

A consistent positive, albeit not strong, correlation between $\mathrm{Hg}^{0}$ and temperature was observed in spring at a remote rural location situated above the boundary layer half of the time and in summer at a sea level coastal site. No such correlation was found at a site in the marine boundary layer. Our previous study found significant correlation between $\mathrm{Hg}^{0}$ and temperature averaged at each hour of a day over the seasons of spring and fall 2007 at TF (coastal) and AI (marine) (Sigler et al., 2009a), and speculated that higher $\mathrm{Hg}^{0}$ may be attributed to thermally and/or photochemically mediated release from soil (e.g., Poissant and Casimir, 1998; Sigler and Lee, 2006). The lack of consistent $\mathrm{Hg}^{0}$-temperature correlation in the marine boundary layer during the warm season seems to support this speculation.

Higher levels of RGM was observed at warmer temperatures during the warm season (i.e., spring and summer) and this tendency was enhanced for daytime data in the coastal, 


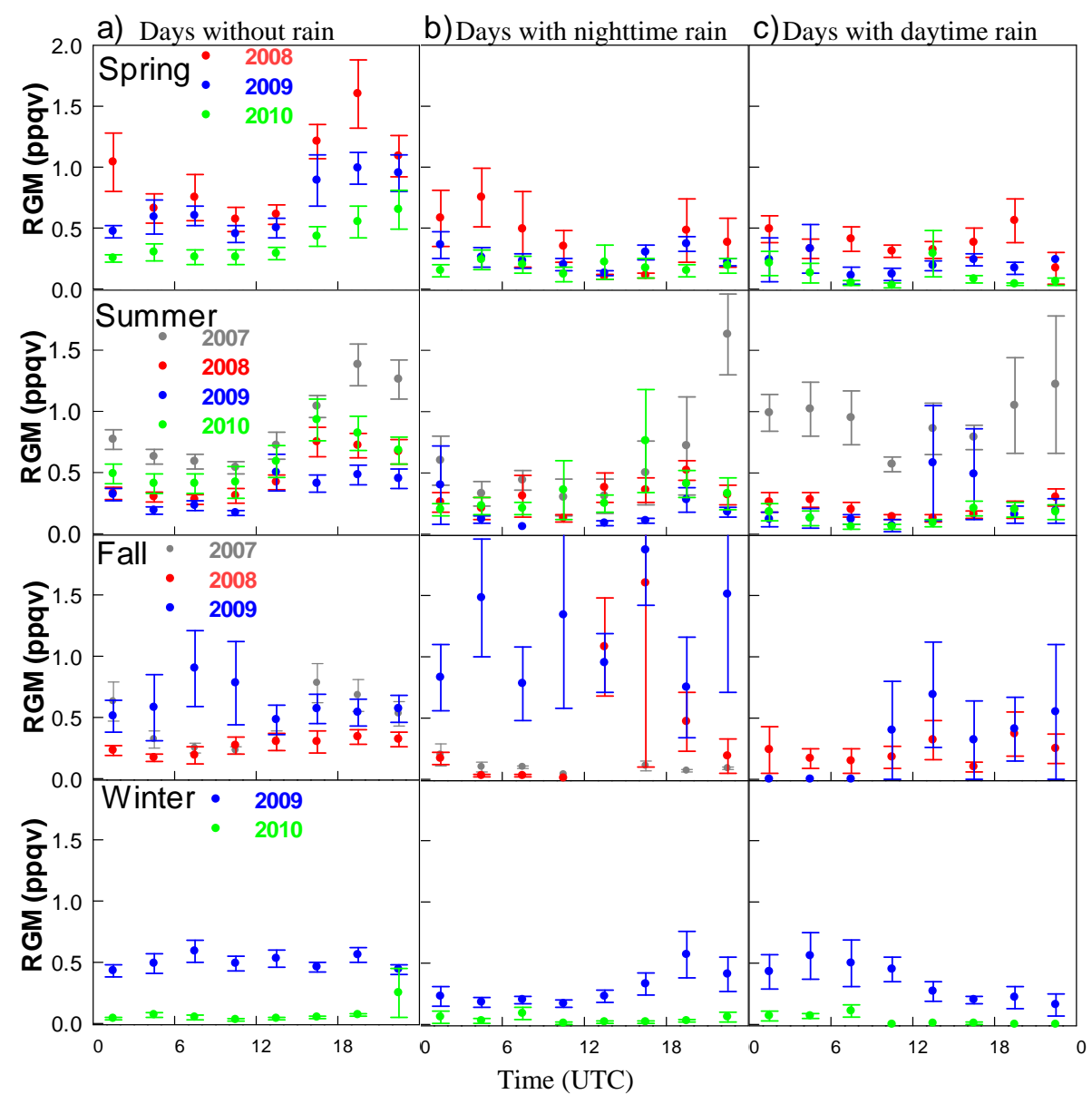

Fig. 17. Diurnal cycles of RGM at AI (marine) averaged over days without rain (a), days with nighttime rain (b), and days with daytime rain (c) for all seasons during 2007-2010. Precipitation in winter includes rain and snow. Local nighttime is about 00:00-11:00 UTC, daytime 12:00-23:00 UTC, and noontime is 16:00 UTC during the Daylight Saving period of the year and 17:00 UTC otherwise.

marine, and inland environments. Lesser scavenging in winter possibly led to detectable 75 th percentile values at the inland site. Since the diurnal and seasonal cycles of temperature and solar radiation are intricately associated, it is impossible to ascertain whether and how much of increasing RGM levels could be attributed to temperature and/or solar radiation separately.

The inland site is situated above the boundary layer, i.e., in the free troposphere, half of the time and hundreds of kilometers downwind of major source regions, measurements from this site capture variability in RGM in the free troposphere over rural areas. The seasonal variability at that site suggests that in the midlatitude free troposphere without direct influence of major anthropogenic sources: (1) RGM mixing ratios were mostly below the LOD, (2) the mixing ratios exceeding the LOD exhibited a tendency of higher levels at warmer temperature.

There has been limited research on relationships between $\mathrm{Hg}^{\mathrm{P}}$ and temperature. Our data showed two opposite regimes in the $\mathrm{Hg}^{\mathrm{P}}$-temperature relationship: negative and positive correlation at temperatures below and above $8{ }^{\circ} \mathrm{C}$, respectively, corresponded to the cold and warm seasons. At AI (marine) perhaps because of the missing wintertime data, there is only one pattern showing values increased with warming temperature.

The positive relationship between $\mathrm{Hg}^{\mathrm{P}}$ and temperature in warmer seasons possibly reflects the effect of solar radiation on $\mathrm{Hg}$ cycling, i.e., stronger solar radiation conducive to more radicals with subsequent impact on $\mathrm{Hg}^{0}$ oxidation leading to more RGM and subsequently more $\mathrm{Hg}^{\mathrm{P}}$ in the coastal and marine environments. Needless to say the effect of solar radiation on the surface air temperature is a direct one, too, and thus it is logical to hypothesize that the positive correlation between temperature and speciated $\mathrm{Hg}$ (i.e., RGM and $\mathrm{Hg}^{\mathrm{P}}$ ) is more of an indication of common physical mechanisms that drive variation in them than a direct link. This hypothesis is in fact supported by the relationships between $\mathrm{RGM} / \mathrm{Hg}^{\mathrm{P}}$ and radiation flux under no precipitation conditions at the coastal site as well as between $\mathrm{RGM} / \mathrm{Hg}^{\mathrm{P}}$ and $j \mathrm{NO}_{2}$ at the marine site as described in Sect. 3. 


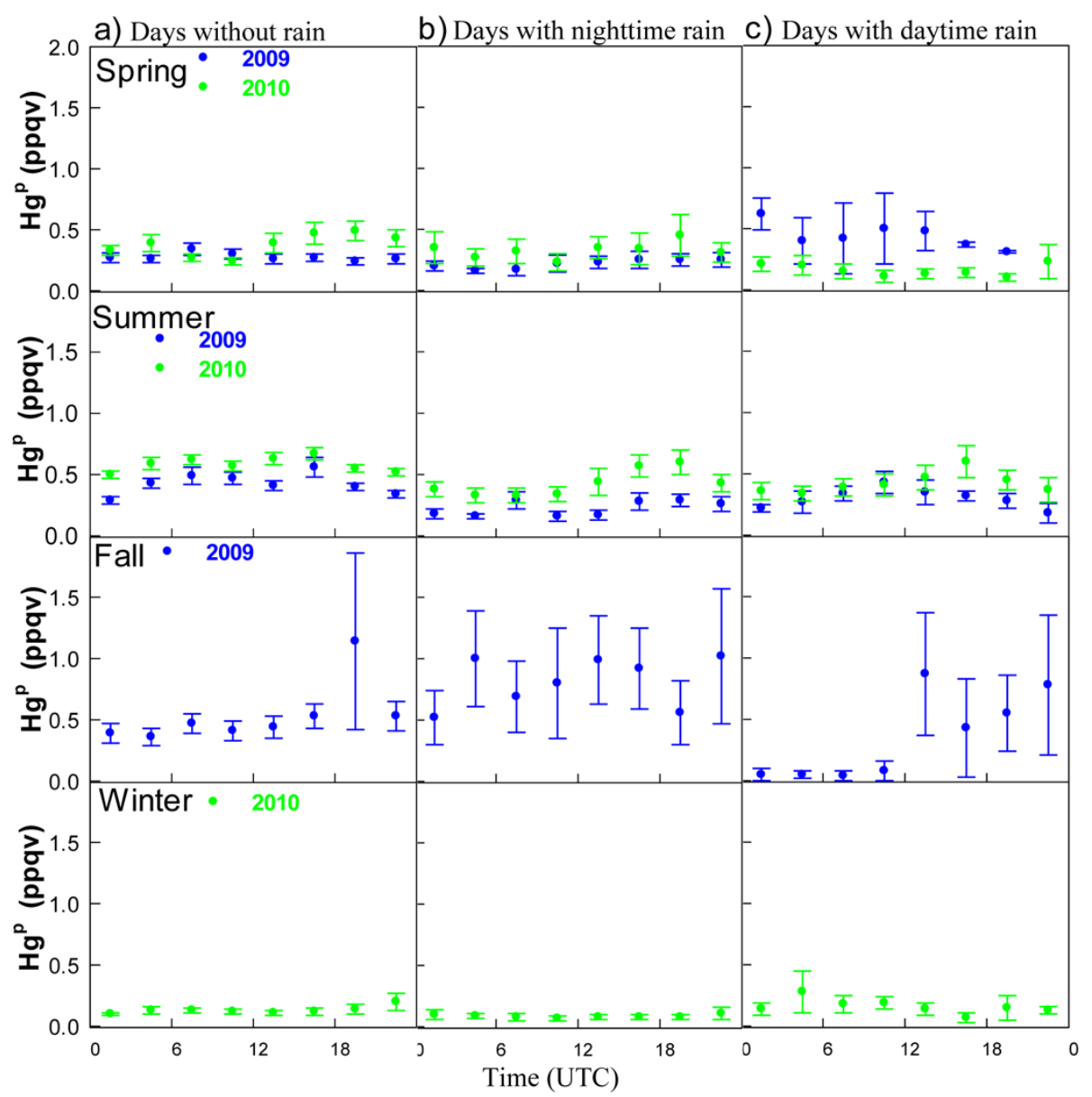

Fig. 18. Diurnal cycles of $\mathrm{Hg}^{\mathrm{P}}$ at $\mathrm{AI}$ (marine) averaged over days without rain (a), days with nighttime rain (b), and days with daytime rain (c) for all seasons during 2009-2010. Precipitation in winter includes rain and snow. Local nighttime is about 00:00-11:00 UTC, daytime 12:00-23:00 UTC, and noontime is 16:00 UTC during the Daylight Saving period of the year and 17:00 UTC otherwise.

\subsection{Relative humidity}

An overall examination revealed no well-defined relationships between $\mathrm{Hg}^{0}$ and relative humidity in all three environments for all seasons. A decreasing tendency in RGM with increasing relative humidity levels in all seasons was observed at the coastal site (TF) as well as the median level of exceeding the LOD at the inland site (PM) in spring and winter at relative humidity $<60 \%$. Faïn et al. (2009) showed that high RGM levels were always observed with relative humidity below 40 to $50 \%$ at Storm Peak Laboratory at an elevation of $3200 \mathrm{~m}$ a.s.1., in Colorado, during the time period of 28 April-1 July 2008 , which was suggested to be related to oxidation of upper tropospheric $\mathrm{Hg}^{0}$. However, we do not believe that there was a straightforward and direct link between higher RGM and lower relative humidity, because in both seasons over $90 \%$ of those higher RGM samples were measured in the time window of 14:00-24:00 UTC, which is the time period of lower relative humidity, stronger solar radiation, and daily maximum RGM production.
Compared to the coastal (TF) and inland (PM) sites, there was less variability in RGM with varying relative humidity in the marine environment (AI), possibly because of smaller range of relative humidity and a larger production rate of RGM involving halogen chemistry which could dominate over the dependence of loss rate on humidity.

\subsection{Precipitation}

A few studies suggested the overall scavenging effect of precipitation on RGM (Yatavelli et al., 2006; Laurier et al., 2007), but none examined the dependence of the scavenging effect on precipitation amount and the impact of precipitation on diurnal variability of speciated mercury in different environments. Consistent with previous work, we also observed that RGM levels dropped immediately below the LOD in rainfalls events independent of the precipitation amount in many cases, while in some cases, mostly in spring and summer, RGM mixing ratios remained above the LOD and even increased during precipitation events. In the latter cases, 
Table 3. Seasonal mean (denoted as avg) $\pm 1 \sigma$ values (ppqv) of RGM at Appledore Island for rainy and dry conditions. $N$ stands for the number of samples.

\begin{tabular}{lcccc}
\hline & \multicolumn{2}{l}{ Rainy } & \multicolumn{2}{l}{ dry } \\
\cline { 2 - 5 } & $N$ & Avg $\pm 1 \sigma$ & $N$ & Avg $\pm 1 \sigma$ \\
\hline Spring 2008 & 57 & $0.30 \pm 0.36$ & 386 & $0.89 \pm 1.22$ \\
2009 & 70 & $0.09 \pm 0.19$ & 537 & $0.69 \pm 1.03$ \\
2010 & 62 & $0.05 \pm 0.11$ & 463 & $0.37 \pm 0.65$ \\
\hline Summer 2007 & 36 & $0.59 \pm 0.40$ & 476 & $0.83 \pm 0.79$ \\
2008 & 64 & $0.17 \pm 0.23$ & 544 & $0.47 \pm 0.66$ \\
2009 & 79 & $0.09 \pm 0.42$ & 276 & $0.37 \pm 0.47$ \\
2010 & 38 & $0.22 \pm 0.53$ & 562 & $0.60 \pm 1.02$ \\
\hline Fall 2006 & 57 & $0.02 \pm 0.02$ & 133 & $0.46 \pm 0.46$ \\
2008 & 59 & $0.08 \pm 0.14$ & 236 & $0.26 \pm 0.36$ \\
2009 & 52 & $0.33 \pm 0.70$ & 255 & $0.59 \pm 0.98$ \\
\hline Winter 2009 & 65 & $0.17 \pm 0.13$ & 293 & $0.50 \pm 0.40$ \\
2010 & 62 & $0.01 \pm 0.03$ & 185 & $0.07 \pm 0.31$ \\
\hline
\end{tabular}

source strengths (e.g., in situ production and transport) most likely overpowered removal of RGM. This is different from the findings of Yatavelli et al. (2006) and Laurier et al. (2007) who observed that RGM was invariably washed out by precipitation in the continental and marine boundary layers.

Scavenging efficiency of snow in winter was observed to be less than that of liquid precipitation, supported by the average RGM levels during snowfalls of four winters remaining above the LOD as shown in Sect. 3.5. This is consistent with the findings of Lombard et al. (2011) in that both the total seasonal $\mathrm{Hg}$ wet deposition and volume-weighted $\mathrm{Hg}$ concentration in rain water reached the annual minimum in winter during their three year sample collection at TF (coastal).

Our study suggested small impact of precipitation on $\mathrm{Hg}^{\mathrm{P}}$ levels in the coastal and marine environments. Feddersen et al. (2012) using bulk filters for measuring $\mathrm{Hg}^{\mathrm{P}}$ suggested a seasonal shift in the aerosol size distribution. Specifically, we found that $\sim 90 \%$ of the $\mathrm{Hg}^{\mathrm{P}}$ was contained in aerosols with aerodynamic diameters $>2$ micrometer $(\mu \mathrm{m})$ at $\mathrm{AI}$ (marine) and TF (coastal) in summer, in winter it shifted almost entirely to the fine fraction $(<1 \mu \mathrm{m})$ below $0.5 \mu \mathrm{m}$ with little detectable in the coarse sizes, and in spring, there was a mixture of fine and coarse fractions. In the same study we also suggested that the Tekran unit may not measure all the $\mathrm{Hg}^{\mathrm{P}}$ on the coarse fractions by comparing the Tekran and bulk filter measurements. Such seasonal shift in the aerosol size distribution and possible limitations of Tekran 1135 measurements of $\mathrm{Hg}^{\mathrm{P}}$ may have contributed to what we have shown here. Therefore, investigation of the efficacy of Tekran 1135 is warranted before we can further study the causes for the observed seasonal difference in the effect of precipitation or any other climate variables on $\mathrm{Hg}^{\mathrm{P}}$.
Table 4. Seasonal mean (denoted as avg) $\pm 1 \sigma$ values (ppqv) of $\mathrm{Hg}^{\mathrm{P}}$ at Appledore Island for rainy and dry conditions. $N$ stands for the number of samples.

\begin{tabular}{lcccc}
\hline & \multicolumn{2}{c}{ Rainy } & \multicolumn{2}{l}{ dry } \\
\cline { 2 - 5 } & $N$ & Avg $\pm 1 \sigma$ & $N$ & Avg $\pm 1 \sigma$ \\
\hline Spring 2009 & 52 & $0.08 \pm 0.13$ & 257 & $0.27 \pm 0.21$ \\
2010 & 62 & $0.11 \pm 0.19$ & 495 & $0.37 \pm 0.52$ \\
\hline Summer 2009 & 79 & $0.09 \pm 0.13$ & 426 & $0.43 \pm 0.38$ \\
2010 & 38 & $0.35 \pm 0.28$ & 625 & $0.58 \pm 0.36$ \\
\hline Fall 2009 & 52 & $0.36 \pm 0.72$ & 364 & $0.54 \pm 2.10$ \\
\hline Winter 2009 & 65 & $0.08 \pm 0.07$ & 193 & $0.13 \pm 0.16$ \\
\hline
\end{tabular}

\section{Summary}

In this study, we present a comprehensive analysis of relationships that $\mathrm{Hg}^{0}$, RGM, and $\mathrm{Hg}^{\mathrm{P}}$ bore with climate variables in inland elevated rural, coastal, and marine environments using 3-7 yr of continuous data sets of high temporal resolution. This extensive analysis of long term measurement data suggested great complexity in the climate impact on ambient levels of speciated mercury. More specifically, there did not appear to be simple and direct linkage between $\mathrm{Hg}^{0} / \mathrm{RGM} / \mathrm{Hg}^{\mathrm{P}}$ and any physical variables; positive or negative effects were indicated by the tendencies in $\mathrm{Hg}^{0} / \mathrm{RGM} / \mathrm{Hg}^{\mathrm{P}}$ mixing ratios corresponding to varying climatic conditions. A few key points on such tendencies are summarized as follows.

- The impact of wind speed on ambient mixing ratios of $\mathrm{Hg}^{0}$ in all three environments was best captured during an occurrence of a strong cyclonic system in November 2008 when winds exceeded $15 \mathrm{~m} \mathrm{~s}^{-1}$ at AI (marine), in agreement with our case study of the April 2007 Nor' easter in Sigler et al. (2009b). The RGM and $\mathrm{Hg}^{\mathrm{P}}$ median, 75th, and 90th percentile values decreased with increasing wind speed in the marine environment indicating enhanced loss through deposition associated with strong winds in the marine boundary layer. At the coastal site RGM mixing ratios were lowest under calm conditions (wind speed $<1 \mathrm{~m} \mathrm{~s}^{-1}$ ) and highest at southerly and southeasterly winds $>2 \mathrm{~m} \mathrm{~s}^{-1}$ suggesting that transport was the primary source of RGM to our study location.

- All metrics in RGM and $\mathrm{Hg}^{\mathrm{P}}$ appeared to increase with stronger solar radiation at the coastal and marine sites.

- The best point-to-point correlation was found between $\mathrm{Hg}^{0}$ and temperature in summer at the coastal location and spring at the inland elevated rural site. No correlation was found in the marine boundary layer. This supports the speculation from our previous study on 
Table 5. Summary of key results in the coastal, marine, and inland environments.

\begin{tabular}{|c|c|c|c|c|}
\hline & & Coastal (TF) & Marine (AI) & Inland elevated rural (PM) \\
\hline \multirow{2}{*}{ Wind } & RGM & Transport and local production & $\begin{array}{l}\text { No dependence except values } \\
>4 \text { ppqv attributed to transport }\end{array}$ & $\begin{array}{l}\text { The very few points > LOD associated } \\
\text { with upwind coal-fired power plants }\end{array}$ \\
\hline & $\mathrm{Hg}^{\mathrm{P}}$ & No apparent dependence & $\begin{array}{l}\text { A decreasing tendency with in- } \\
\text { creasing wind speed indicating de- } \\
\text { position } \\
\text { Values of } 0.5-1.5 \text { ppqv attributed } \\
\text { to continental influence }\end{array}$ & $\overline{-}_{\text {(no } \mathrm{Hg}^{\mathrm{P}} \text { data) }}$ \\
\hline \multirow[t]{2}{*}{$\begin{array}{l}\text { Solar } \\
\text { Radiation }\end{array}$} & $\mathrm{Hg}^{0}$ & No dependence & No dependence & $\begin{array}{l}- \\
\text { (no radiation data) }\end{array}$ \\
\hline & RGM & $\begin{array}{l}\text { Positive tendency in spring } \\
\text { linked to production }\end{array}$ & $\begin{array}{l}\text { Positive tendency in spring and } \\
\text { summer linked to production }\end{array}$ & - \\
\hline \multirow[t]{2}{*}{$\begin{array}{l}\text { Tempera- } \\
\text { ture }\end{array}$} & $\mathrm{Hg}^{0}$ & $\begin{array}{l}\text { Positive correlation, linked to } \\
\text { thermal and/or photochemi- } \\
\text { cally mediated release from } \\
\text { soil }\end{array}$ & No correlation & $\begin{array}{l}\text { Positive correlation, linked to thermal } \\
\text { and/or photochemically mediated re- } \\
\text { lease from soil }\end{array}$ \\
\hline & RGM & $\begin{array}{l}\text { Higher RGM with warmer } \\
\text { temperatures during the warm } \\
\text { season }\end{array}$ & $\begin{array}{l}\text { RGM }>\text { LOD at warmer tempera- } \\
\text { tures during the warm season } \\
\text { Detectable } 75 \text { th percentile values } \\
\text { in winter }\end{array}$ & $\begin{array}{l}\text { Higher RGM with warmer temperatures } \\
\text { during the warm season }\end{array}$ \\
\hline
\end{tabular}

thermally and/or photochemically mediated release of $\mathrm{Hg}^{0}$ from soil. RGM and $\mathrm{Hg}^{\mathrm{P}}$ at all sites showed positive tendencies with increasing temperature in spring, summer, and fall.

- Relationships between RGM and relative humidity in the coastal area suggested a clear decreasing tendency in all metrics, including 10th, 25th, median, 75th, and 90th percentile values, from less than $40 \%$ to $100 \%$ relative humidity levels in all seasons especially in spring. No relationship between relative humidity and $\mathrm{Hg}^{\mathrm{P}}$ mixing ratios was observed for all seasons in the marine boundary layer, whereas at the coastal location correlation was observed for summers.

- The effect of precipitation on RGM at the coastal and marine locations was similar. RGM levels remained around $0.2 \mathrm{ppqv}$ under rainy conditions and a factor of 3-4 to two orders of magnitude higher under dry conditions in spring. In winter RGM mix- ing ratios appeared to be mostly above LOD during snowfalls at $0.14 \pm 0.20,0.18 \pm 0.33,0.45 \pm 0.23$, and $0.14 \pm 0.21 \mathrm{ppqv}$ for the 2007-2010 winters at TF (coastal), suggesting less scavenging efficiency of snow. Precipitation had negligible impact on the magnitude and pattern of diurnal variation of $\mathrm{Hg}^{\mathrm{P}}$ at the marine site AI (marine) in all seasons.

Many questions from this study remain to be addressed, e.g., quantifying strong wind induced oceanic evasion, mechanisms driving the positive correlations between mercury and temperature/solar radiation, and less impact of relative humidity and precipitation on $\mathrm{Hg}^{\mathrm{P}}$ than on RGM. In addition, longer continuous measurement data of $\mathrm{Hg}^{0}, \mathrm{RGM}$, and $\mathrm{Hg}^{\mathrm{P}}$ are imperative to obtain rigorous quantification of their relationships with climate variables. Future research is warranted to obtain in-depth knowledge of the mechanisms driving those relationships. 
Table 5. Continued.

\begin{tabular}{|c|c|c|c|c|}
\hline & & Coastal (TF) & Marine (AI) & Inland elevated rural (PM) \\
\hline $\begin{array}{l}\text { Relative } \\
\text { Humidity }\end{array}$ & RGM & $\begin{array}{l}\text { Lowest at } \mathrm{RH}=100 \% \\
\text { highest at } \mathrm{RH}<40 \%\end{array}$ & $\begin{array}{l}\text { Less variability over all bins of } \\
\mathrm{RH} \text {; highest levels in summer } \\
\text { when } \mathrm{RH}<50 \%\end{array}$ & $\begin{array}{l}\text { In spring and winter for } \mathrm{RH}<60 \% \text { the } \\
\text { median level of RGM exceeded the LOD }\end{array}$ \\
\hline \multirow{3}{*}{$\begin{array}{l}\text { Precipi- } \\
\text { tation }\end{array}$} & $\mathrm{Hg}^{0}$ & No dependence & No dependence & No dependence \\
\hline & RGM & $\begin{array}{l}\text { In summer } 95 \% \text { of the data } \\
\text { during rainfalls <LOD and } \\
80 \% \text { in fall; in spring more } \\
\text { data > LOD, and mostly } \\
>\text { LOD during snowfalls in } \\
\text { winter. } \\
\text { Diurnal variation dampened } \\
\text { greatly on days with nighttime } \\
\text { rain and flattened with daytime } \\
\text { rain. } \\
\text { Falling <LOD immediately } \\
\text { after a rainfall began nearly in- } \\
\text { dependent of rain amount. } \\
12 \text { events with RGM increas- } \\
\text { ing during a rainfall, } 4 \text { of them } \\
\text { lasting } 9-19 \mathrm{~h} \text { with RGM con- } \\
\text { sistently remaining }>\text { LOD }\end{array}$ & $\begin{array}{l}\text { Nighttime and daytime precipita- } \\
\text { tion dampened diurnal variability } \\
\text { lowering RGM throughout the day } \\
\text { in the warm season. } \\
\text { In winter nighttime/daytime } \\
\text { precipitation suppressed night- } \\
\text { time/daytime levels only. }\end{array}$ & - \\
\hline & $\mathrm{Hg}^{\mathrm{P}}$ & $\begin{array}{l}\text { Less impact on diurnal vari- } \\
\text { ability and patterns than those } \\
\text { of RGM }\end{array}$ & Negligible impact & - \\
\hline
\end{tabular}

Acknowledgements. Funding for this work is provided by the National Science Foundation under grant\# ATG1141713, the National Oceanic and Atmospheric Administration AIRMAP program under grant\# NA07OAR4600514, and the Environmental Protection Agency under contract \#EP09H000355. A fraction of meteorological data for the marine site AI was obtained from GoMOOS (http://www.gomoos.org/index.html). We thank Cheryl Parker and Kevan Carpenter for their technical assistance. We thank J. Sigler for his work on initiating and maintaining RGM measurement at AIRMAP sites. We thank Referee \#1 for his/her conscientious reviews; his/her constructive comments and suggestions helped us improve the manuscript.

Edited by: R. Cohen

\section{References}

Ames, M., Gullu, G., and Olmez, I.: Atmospheric mercury in the vapor phase, and in fine and coarse particulate matter at Perch River, New York, Atmos. Environ., 32, 865-872, 1998.

Aucott, M. L., Caldarelli, A. D., Zsolway, R. R., Pietarinen, C. B., and England, R.: Ambient elemental, reactive gaseous, and particle-bound mercury concentrations in New Jersey, U.S.: measurements and association with wind direction, Environ. Monit. Assess., 158, 295-306, 2009.

Baya, A. P. and Van Heyst, B.: Assessing the trends and effects of environmental parameters on the behaviour of mercury in the lower atmosphere over cropped land over four seasons, Atmos. Chem. Phys., 10, 8617-8628, doi:10.5194/acp-10-86172010, 2010.

Brooks, S., Luke, W., Cohen, M., Kelly, P., Lefer, B., and Rappenglück, B.: Mercury species measured atop the Moody Tower TRAMP site, Houston, Texas, Atmos. Envrion., 44, 4045-4055, 2010. 
Castillo, A., Valdes, J., Sibaja, J., Vega, I., Alfaro, R., Morales, J., Esquivel, G., Barrantes, E., Black, P., and Lean, D.: Seasonal and diel patterns of total gaseous mercury concentration in the atmosphere of the Central Valley of Costa Rica, Appl. Geochem., 26, 242-248, 2011.

Cobbetta, F. D., Steffen, A., Lawson, G., and Van Heyst, B. J.: GEM fluxes and atmospheric mercury concentrations (GEM, RGM and $\left.\mathrm{Hg}^{P}\right)$ in the Canadian Arctic at Alert, Nunavut, Canada (February-June 2005), Atmos. Environ., 41, 6527-6543, 2007.

Cole, A. S. and Steffen, A.: Trends in long-term gaseous mercury observations in the Arctic and effects of temperature and other atmospheric conditions, Atmos. Chem. Phys., 10, 4661-4672, doi:10.5194/acp-10-4661-2010, 2010.

Engle, M. A., Tate, M. T., Krabbenhoft, D. P., Kolker, A., Olson, M. L., Edgerton, E. S., DeWild, J. F., and McPherson, A. K.: Characterization and cycling of atmospheric mercury along the central U.S. Gulf Coast, Appl. Geochem., 23, 419-437, doi:10.1016/j.apgeochem.2007.12.024, 2008.

Faïn, X., Obrist, D., Hallar, A. G., Mccubbin, I., and Rahn, T.: High levels of reactive gaseous mercury observed at a high elevation research laboratory in the Rocky Mountains, Atmos. Chem. Phys., 9, 8049-8060, doi:10.5194/acp-9-8049-2009, 2009.

Feddersen, D., Talbot, R., Mao, H., and Sive, B.: Size distribution of Atmospheric particulate mercury in marine and coastal atmospheres, Atmos. Chem. Phys. Discuss., accepted, 2012.

Gårdfeldt, K., Sommar, J., Ferrara, R., Ceccarini, C., Lanzilotta, E., Munthe, J., Wangberg, I., Lindqvist, O., Pirrone, N., Sprovieri, P., and Pesenti, E.: Evasion of mercury from Atlantic coastal water and the Mediterranean sea, coastal and open water, Atmos. Environ., 37, Suppl. 1, 73-84, 2003.

Gabriel, M. C., Williamson, D. G., Brooks, S., and Lindberg, S.: Atmospheric speciation of mercury in two contrasting Southeastern US airsheds, Atmos. Environ., 39, 4947-4958, 2005.

Han, Y.-J., Holsen, T. M., Lai, S.-O., Hopke, P. K., Yi, S.-M., Liu, W., Pagano, J., Falanga, L., Milligan, M., and Andolina, C.: Atmospheric gaseous mercury concentrations in New York State: relationships with meteorological data and other pollutants, Atmos. Environ., 38, 6431-6446, 2004.

Holmes, C. D., Jacob, D. J., Mason, R. P., and Jaffe, D. A.: Sources and deposition of reactive gaseous mercury in the marine atmosphere, Atmos. Environ., 43, 2278-2285, 2009.

Jacob, D. and Winner, D. A.: Effect of climate change on air quality, Atmos. Environ., 43, 51-63, 2009.

Kock, H. H., Bieber, E., Ebinghaus, R., Spain, T. G., and Thees, B.: Comparison of long-term trends and seasonal variations of atmospheric mercury concentrations at the two European coastal monitoring stations Mace Head, Ireland, and Zingst, Germany, Atmos. Environ., 39, 7549-7556, 2005.

Laurier, F. J. G., Mason, R. P., and Whalin, L.: Reactive gaseous mercury formation in the North Pacific Ocean's marine boundary layer: A potential role of halogen chemistry, J. Geophys. Res., 108, 4529, doi:10.1029/2003JD003625, 2003.

Laurier, F. and Mason, R.: Mercury concentration and speciation in the coastal and open ocean boundary layer, J. Geophys. Res., 112, D06302, doi:10.1029/2006JD007320, 2007.

Li, Z., Xia, C., Wang, X., Xiang, Y., and Xie, Z.: Total gaseous mercury in Pearl River Delta region, China during 2008 winter period, Atmos. Environ., 45, 834-838, 2011.
Lin, C.-J. and Pehkonen, S. O.: The chemistry of atmospheric mercury : a review, Atmos. Environ., 33, 2067-2079, 1999.

Liu, B., Keeler, G. J., Dvonch, J. T, Barres, J. A., Lynam, M. M., Marsik, F. J., and Morgan, J. T.: Temporal variability of mercury speciation in urban air, Atmos. Environ., 41, 1911-1923, 2007.

Lombard, M. A. S., Bryce, J. G., Mao, H., and Talbot, R.: Mercury deposition in Southern New Hampshire, 2006-2009, Atmos. Chem. Phys., 11, 7657-7668, doi:10.5194/acp-11-76572011, 2011.

Mao, H. and Talbot, R.: $\mathrm{O}_{3}$ and $\mathrm{CO}$ in New England: Temporal variations and relationships, J. Geophys. Res., 109, D21304, doi:10.1029/2004JD004913, 2004a.

Mao, H. and Talbot, R.: The role of meteorological processes in two New England ozone episodes during summer 2001, J. Geophys. Res., 109, D20305, doi:10.1029/2004JD004850, 2004b.

Mao, H., Talbot, R. W., Sigler, J. M., Sive, B. C., and Hegarty, J. D.: Seasonal and diurnal variations of $\mathrm{Hg}^{0}$ over New England, Atmos. Chem. Phys., 8, 1403-1421, doi:10.5194/acp-8-1403-2008, 2008.

Mao, H. and Talbot, R.: Speciated mercury at marine, coastal, and inland sites in New England - Part 1: Temporal variability, Atmos. Chem. Phys. Discuss., 11, 32301-32336, doi:10.5194/acpd-11-32301-2011, 2011.

Mao, H., and Talbot, R., et al.: Speciated Mercury at Marine, Coastal, and Inland Sites in New England: Part III. Relationships with Key Trace Gases, Atmos. Chem. Phys. Discuss., in preparation, 2012.

Mason, R. P. and Sheu, G.-R.: Role of the ocean in the global mercury cycle, Global Biogeochem. Cy., 16, 1093, doi:10.1029/2001GB001440, 2002.

Pirrone, N., Hedgecock, I. M., and Forlano, L.: The role of the ambient aerosol in the atmospheric processingof semivolatile contaminants: A parameterised numerical model (gaspar), J. Geophys. Res., 105, 9773-9790, 2000.

Poissant, L. and Casimir, A.: Water-air and soil-air exchange rate of total gaseous mercury at background sites, Atmos. Environ., 32, 883-893, 1998.

Poissant, L., Pilote, M., Xu, X., Zhang, H., and Beauvais, C.: Atmospheric mercury speciation and deposition in the Bay St. François wetlands, J. Geophys. Res., 109, D11301, doi:1029/2003JD004364, 2004.

Poissant, L., Pilote, M., Xu, X., Beauvais, C., Constant, P., and Zhang, H.: A year of continuous measurements of three atmospheric mercury species in southern Quebec, Canada, Atmos. Environ., 39, 1275-1287, 2005.

Rothenberg, S. E., McKee, L., Gilbreath, A., Yee, D., Connor, M., and $\mathrm{Fu}, \mathrm{X}$.: Short-range transport of atmospheric mercury to a rural, inland site, Atmos. Environ., 44, 1263-1273, 2010.

Sigler, J. M. and Lee, X.: Gaseous mercury in background forest soil in the northeastern United States, J. Geophys. Res., 111, G02007, doi:10.1029/2005JG000106, 2006.

Sigler, J. M., Mao, H., and Talbot, R.: Gaseous elemental and reactive mercury in Southern New Hampshire, Atmos. Chem. Phys., 9, 1929-1942, doi:10.5194/acp-9-1929-2009, 2009a.

Sigler, J. M., Mao, H., Sive, B. C., and Talbot, R.: Oceanic influence on atmospheric mercury at coastal and inland sites: a springtime noreaster in New England, Atmos. Chem. Phys., 9, 4023-4030, doi:10.5194/acp-9-4023-2009, 2009 b. 
Sprovieri, F., Pirrone, N., and Sommar, J.: Mercury speciation in the marine boundary layer along a $6000 \mathrm{~km}$ cruise path around the Mediterranean Sea, Atmos. Environ., 37, Suppl. 1, S63-S71, 2003.

Stamenkovic, J., Lyman, S., and Gustin, M. S.: Seasonal and diel variation of atmospheric mercury concentrations in the Reno (Nevada, USA) airshed, Atmos. Environ., 41, 6662-6672, 2007.

Talbot, R., Mao, H., Feddersen, D., Smith, M., Kim, S. Y., Sive, B., Haase, K., Ambrose, J., Zhou, and Russo R.: Comparison of particulate mercury measured with manual and Y. automated methods, Atmosphere, 2, 1-20, doi:10.3390/atmos2010001, 2011.
Yatavelli, R. L. N., Fahrni, J. K., Kim, M., Crist, K. C., Vickers, C. D., Winter, S. E., and Connell, D. P.: Mercury, PM $_{2.5}$ and gaseous co-pollutants in the Ohio River Valley region: Preliminary results from the Athens supersite, Atmos. Environ., 40, 6650-6665, 2006.

Zhou, Y., Mao, H., Russo, R. S., Blake, D. R., Wingenter, O. W., Haase, K. B., Varner, R. K., Talbot, R., and Sive, B. C.: Bromoform and dibromomethane measurements in the seacoast region of New Hampshire, 2002-2004, J. Geophys. Res., 113, D08305, doi:10.1029/2007JD009103, 2008. 